\title{
Science and technology in high-entropy alloys
}

\author{
Weiran Zhang ${ }^{1}$, Peter K. Liaw ${ }^{2}$ and Yong Zhang ${ }^{1,3^{*}}$
}

\begin{abstract}
As human improve their ability to fabricate materials, alloys have evolved from simple to complex compositions, accordingly improving functions and performances, promoting the advancements of human civilization. In recent years, high-entropy alloys (HEAs) have attracted tremendous attention in various fields. With multiple principal components, they inherently possess unique microstructures and many impressive properties, such as high strength and hardness, excellent corrosion resistance, thermal stability, fatigue, fracture, and irradiation resistance, in terms of which they overwhelm the traditional alloys. All these properties have endowed HEAs with many promising potential applications. An in-depth understanding of the essence of HEAs is important to further developing numerous HEAs with better properties and performance in the future. In this paper, we review the recent development of HEAs, and summarize their preparation methods, composition design, phase formation and microstructures, various properties, and modeling and simulation calculations. In addition, the future trends and prospects of HEAs are put forward.
\end{abstract}

Keywords: high-entropy alloys, multiple principal components, microstructures and properties, phase formation, modeling and simulation calculations

\section{INTRODUCTION}

Metals and alloys have a long history, and they have been playing an irreplaceable role in the progress of human civilization. As shown in Fig. 1, the Bronze appeared as early as in Shang Dynasty, lasting over 1,000 years, and the Iron Age lasted about 3,000 years starting from the Spring and Autumn Warring States period [1]. The application of $\mathrm{Al}$ alloys has also been developed for one century [2], even $\mathrm{Ti}$ alloys for more than sixty years [3]. Till now, metals and alloys have been closely involved in all aspects of our lives, including agriculture, housing, transportation, food, machinery, and defense industries.

As illustrated in Fig. 1, in the early stage of alloy, one principal element was fused with other elements in trace amount to improve the specific properties. Today, the design concept of many essential alloys is considered as the traditional alloy-design strategy, such as Fe alloys [4,5], $\mathrm{Cu}$ alloys [6,7], Al alloys [8], Mg alloys [9,10], Ti alloys [11], and $\mathrm{Ni}$ alloys [12]. However, the chemical composition of modern alloys is greatly expanded, for example, Inconel 718 superalloy, which is a representative of $\mathrm{Ni}$ alloy, contains a variety of other elements [13] in addition to $\mathrm{Ni}$. One of the three basic principles of bulk amorphous formation gives a description that an alloy contains at least three elements $[14,15]$. Through careful analysis, it is found that the alloys in Fig. 1 are still deeply influenced by the traditional alloy-design concept. While for further improving the properties, the traditional design paradigm meets with the bottleneck. Fortunately, the complexity of the elemental composition in alloys has been increasing steadily with time as illustrated in Fig. 1.

Crystalline multi-principal element alloys and highentropy alloys (HEAs) were first independently reported in 2004 by Cantor et al. [16] and Yeh et al. [17], which refer to the same concept. Different from the traditional alloy-design concept, HEAs are not based on only one or two elements but contain at least five principal elements in an equal or near-equal atomic percentage (at.\%) with no obvious difference between the solute and solvent [17]. According to the existing physical-metallurgy and phase diagrams, such multi-element alloys may produce many phases and intermetallic compounds, resulting in complex and brittle microstructures that are difficult to analyze and engineer, but probably have finite practical values [18]. Beyond expectations, experimental results indicate that the higher mixing entropy in these alloys enhances the formation of random solid-solution phases

\footnotetext{
${ }^{1}$ State Key Laboratory for Advanced Metals and Materials, University of Science and Technology Beijing, Beijing 100083, China

${ }^{2}$ Department of Materials Science and Engineering, University of Tennessee, Knoxville, TN 37996, USA

${ }^{3}$ Beijing Key Laboratory for Magneto-Photoelectrical Composite and Interface Science, University of Science and Technology Beijing, Beijing 100083, China

* Corresponding author (email: drzhangy@ustb.edu.cn)
} 


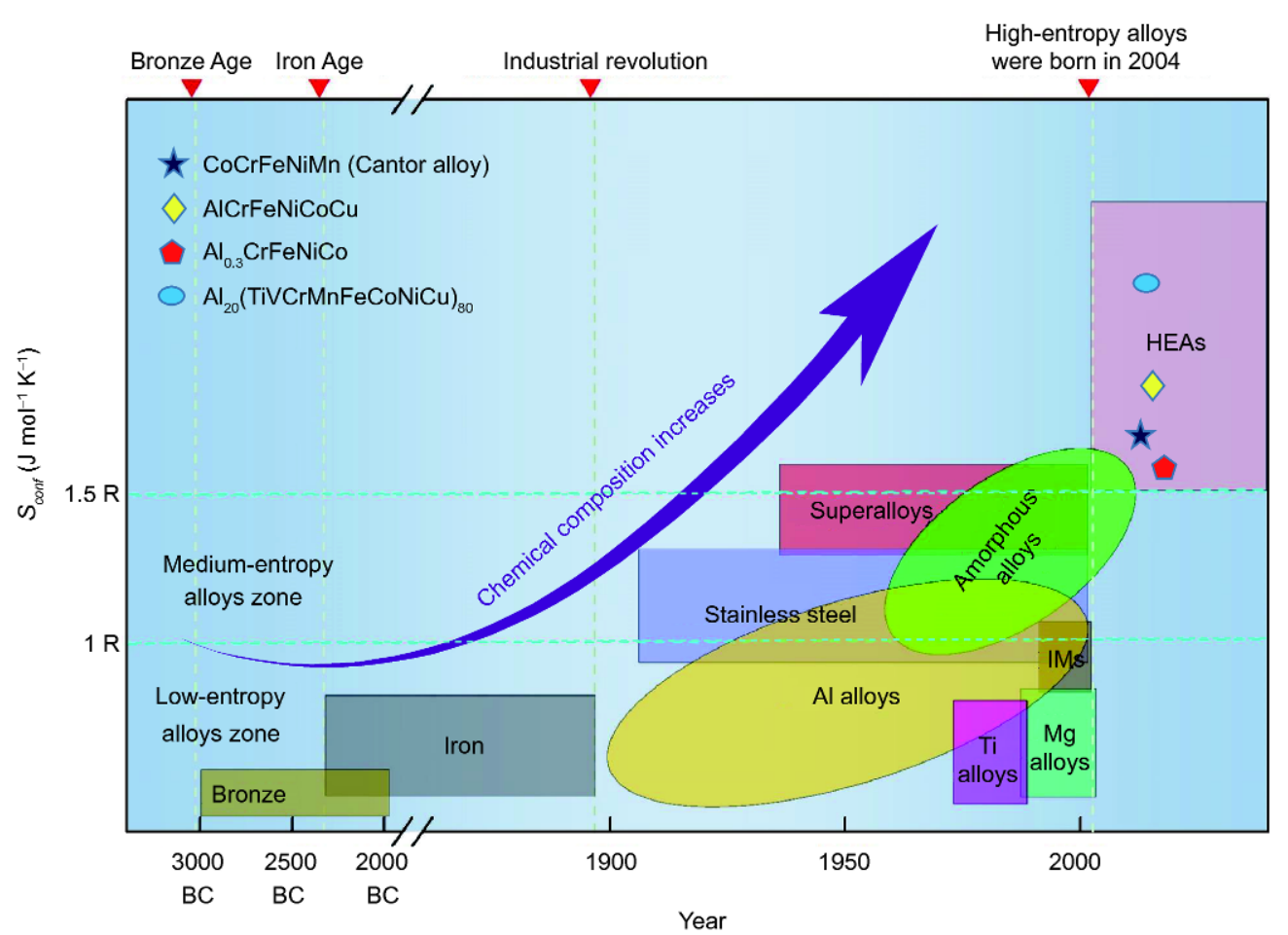

Figure 1 Rising trend of alloy chemical complexity versus time (IMs: intermetallics or metallic compounds, HEA: high-entropy alloy). Reproduced with the permission from Ref. [1]. Copyright 2017, Springer.

with simple structures, such as face-centered-cubic (FCC), body-centered-cubic (BCC), or hexagonal-closepacking (HCP) structures, and thus reduces the number of phases [19-29]. Since then, the new alloy-design strategy opens a huge, unexplored field of multi-component alloys. The strategy of alloy design has obtained unimaginable successes and great efforts have been devoted to the development and application of many HEAs $[30,31]$ in various fields due to their excellent performance, such as the unique wear resistance [32], excellent strength and thermal stability at elevated temperatures $[33,34]$, superior high elongation $[35,36]$, great fatigue and fracture resistance [37-39], etc.

Up to now, thousands of reports on HEAs have been published, including the excellent book "High-entropy Alloys: Fundamentals and Applications" [40], and several review papers [19,20,41-45] covering almost every aspects of current research on HEAs. However, our understanding and research on HEAs is just the tip of the iceberg, and more unexplored secrets of HEAs are disclosed continuously. Due to their remarkable properties and promising research prospects, many new findings in HEAs are emerging beyond the existing review papers and books $[40,41]$. This paper summarizes the recent progress of HEAs, provides a supplement to the research content of HEAs, and forecasts the future development of HEAs.

\section{DEFINITIONS}

There are two definitions of HEAs by composition and entropy, which lead to some confusion and controversy that whether the multi-component alloy could be regarded as HEAs [30].

\section{Composition-based definition}

The earliest composition-based definition was published in 2004 [17]. HEAs were preferentially defined as alloys containing at least 5 principal elements, each with an atomic percentage (at.\%) between $5 \%$ and $35 \%$. It is worth mentioning that the atomic percentage of each minor element, if any, is even smaller than $5 \%$. The definition is expressed as follows $[18,20,40]$ :

$$
\begin{aligned}
& n_{\text {major }} \geq 5,5 \text { at } . \% \leq c_{i} \leq 35 \text { at. } \% \\
& \text { and } n_{\text {minor }} \geq 0, c_{j} \leq 5 \text { at. } \%,
\end{aligned}
$$

where $n_{\text {major }}$ and $n_{\text {minor }}$ are the numbers of major and minor elements, respectively. $c_{i}$ and $c_{j}$ are the atomic percentages of the major element, $i$, and the minor ele- 
ment, $j$, respectively. From this definition, HEAs need not to be equimolar or near-equimolar, and even contain minor elements to balance various materials properties, such as the ductility, toughness, strength, creep, oxidation, etc. $[32,46,47]$.

\section{Entropy-based definition}

Entropy is a thermodynamic state function, and the essence of entropy is "inherent chaos" of the system [20]. According to the Boltzmann's thermodynamic statistics principle, the quantitative relationship between the entropy and randomness of the system is given by:

$$
\Delta S_{\text {conf }}=k \ln w
$$

where $k$ is the Boltzmann's constant, and $w$ is the number of distinguishable ways of arranging the atoms in the solution. The total mixing entropy has four contributions: configurational entropy, $\Delta S_{\text {mix }}^{\text {conf }}$, vibrational entropy, $\Delta S_{\text {mix }}^{\text {vib }}$, magnetic dipole entropy, $\Delta S_{\text {mix }}^{\text {mag }}$, and electronic randomness entropy, $\Delta S_{\text {mix }}^{\text {elec }}$, and the relationship among them is given by:

$$
\Delta S_{\mathrm{mix}}=\Delta S_{\mathrm{mix}}^{\mathrm{conf}}+\Delta S_{\mathrm{mix}}^{\mathrm{vib}}+\Delta S_{\mathrm{mix}}^{\mathrm{elec}}+\Delta S_{\mathrm{mix}}^{\mathrm{mag}} .
$$

The configurational entropy is dominant over the other three contributions. Hence, the configurational entropy often represents the mixing entropy in order to avoid complex calculations to determine the other three contributions [40]. For an ideal random $n$-component solid solution, its ideal configurational entropy per mole is approximately [19]:

$$
\begin{aligned}
\Delta S_{\text {conf }} & =-R\left[c_{1} \ln c_{1}+\ldots+c_{n} \ln c_{n}\right] \\
& =-R \sum_{i=1}^{n} c_{i} \ln c_{i},
\end{aligned}
$$

where $R$ is the gas constant, and $c_{i}$ is the mole fraction of the $i^{\text {th }}$ element, and $n$ is the number of the components. According to the extreme theorem, when $c_{1}=c_{2}=\ldots=c_{n}$, the entropy of the system reaches its maximum value.

Considering an equi-atomic alloy in its liquid state or regular solid-solution state, its configurational entropy per mole could be calculated as [30]:

$$
\Delta S_{\text {conf }}=R \ln n .
$$

It defines that HEAs have a configurational entropy in a random state larger than $1.5 R$, no matter they are single phase or multiphases at room temperature. This definition could be expressed as [48]:

$$
\Delta S_{\text {conf }}>1.5 R \text {. }
$$

\section{Developing definitions}

Although each definition of HEAs contains a wide range of alloys, both definitions overlap for the most part. Despite these definitions, the compositions in non-overlapping regions are also regarded as HEAs. For example, the maximum configurational entropy of a 5-component HEA is $1.61 R\left(\Delta S_{\text {conf }}=R \ln 5=1.61 R\right)$ for the equimolar alloy, and the minimum value of the configurational entropy is $1.36 R$ for an alloy with $35 \%$ A, $35 \%$ B, $20 \%$ C, $5 \%$ $\mathrm{D}$, and $5 \% \mathrm{E}$ (atomic percentage, $\Delta S_{\text {conf }}=-R(2 \times 0.35 \times$ $\ln 0.35+0.2 \times \ln 0.2+2 \times 0.05 \times \ln 0.05)=1.36 R)$. The latter alloy is also considered as an HEA by the composition-based definition but cannot fit into the entropy-based definition. Another example is an equimolar alloy containing 25 elements, with a concentration of 4 at.\% for each element. This alloy is still considered as an HEA since the value of the configurational entropy is $3.219 R\left(\Delta S_{\text {conf }}=-R\right.$ $(25 \times 0.04 \times \ln 0.04)=3.219 R)$. An alloy with a certain composition fitting only one of the two definitions is regarded as an HEA. In addition, sometimes the quaternary equimolar alloy also considered to be an HEA in literature because its composition and configurational entropy are close to the lower limits of both definitions. Thus, the definitions of HEAs are simply approximate guidelines, not strictly laws $[19,40]$.

From the two definitions and the description of nonoverlapping regions of HEAs, it implies that the basic principle behind HEAs with multiple principal elements is to achieve the high mixing entropy in order to enhance the formation of solid-solution phases. As $1.5 R$ is a lower limit for HEAs, we further define medium-entropy alloys (MEAs) and low-entropy alloys (LEAs) to differentiate the power of the mixing entropy effect for all alloys in the nature. Herein, $1 R$ is the boundary between MEAs and LEAs since the mixing entropy less than $1 R$ is expected to be noncompetitive with a larger mixing enthalpy [40].

Thus, the alloys are divided into the following three categories and illustrated in Fig. 2 [48]:

LEAs: $\Delta S_{\text {conf }}<1 R$, including traditional alloys based on one or two elements;

MEAs: $1 R \leq \Delta S_{\text {conf }} \leq 1.5 R$, including alloys based on two to four elements;

HEAs: $\Delta S_{\text {conf }}>1.5 R$, including alloys based on five elements at least or some quaternary equimolar alloys.

It should be noted that among various thermodynamic factors, such as the mixing enthalpy, mixing entropy, atomic-size difference, valence-electron concentration, and electronegativity, the mixing entropy is the sole factor, which rises with increasing the number of principal elements. The name "high-entropy alloys" is pertinent for MPEAs (multiple principal elements alloys) [32,49-51]. Various names have appeared with the development of 


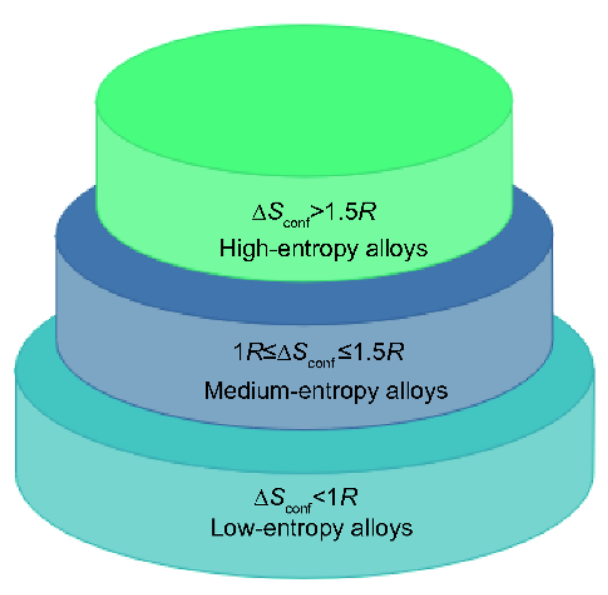

Figure 2 Alloys world based on the configurational entropy.

HEAs, such as complex concentrated alloys (CCAs) [19,52], complex multicomponent alloys (CMAs) [46,53], compositionally complex alloys (CCAs) [40], baseless alloys (BAs) [19], metal buffets (MBs) [45], etc.

\section{PREPARATION OF HEAs}

The discovery of HEAs is related to the study of bulk amorphous alloys [20]. Therefore, the preparation method of HEAs has inherited from the preparation technique of amorphous alloys, which can be divided into three major routes [40], as shown in Fig. 3. The main route is liquid mixing, including arc melting, electricresistance melting, inductive melting, laser melting, laser cladding, and laser engineered net shaping (LENS) [52]. The second route is solid mixing, which mainly contains the mechanical alloying and subsequent consolidation process. Another route is gas mixing, including sputter deposition, pulse-laser deposition (PLD) [20], atomiclayer deposition (ALD) [40], molecular-beam epitaxy (MBE) [54], and vapor-phase deposition.

The aforementioned methods could fabricate three-dimensional bulk, two-dimensional film-like, and one-dimensional fibrous HEAs, and the three-dimensional sample block-body-study is the most widely used $[36,39,55,56]$. Among the reported preparation methods, arc melting is the dominant fabrication route to produce bulk HEAs $[20,53,57,58]$. More recently, gradient bulk samples of HEAs were produced by elemental power mixes with LENS apparatus [52]. Due to the inherent compositional complexity and the huge difference in the melting points between the constituent elements, the preparation of HEAs is challenging. Significant elemental segregation occurs during melt solidification and cooling

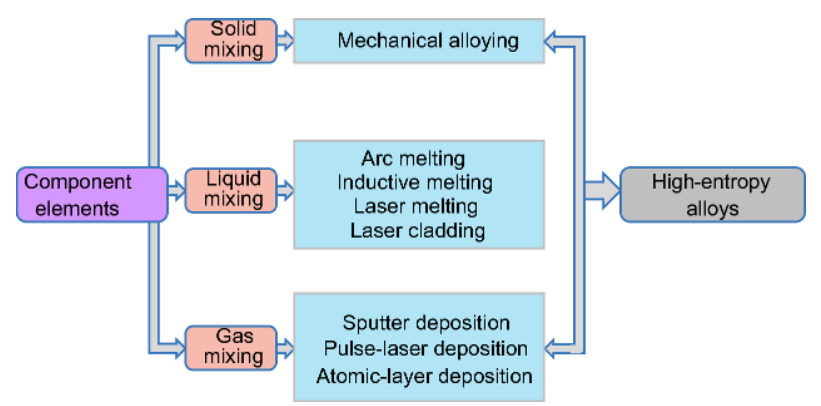

Figure 3 Fabrication routes of HEAs.

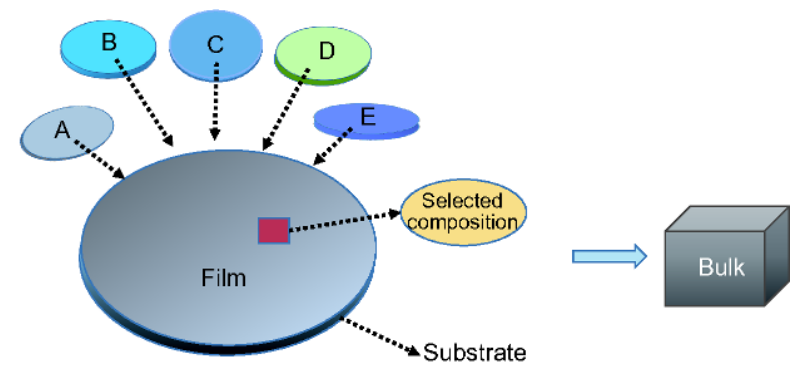

Figure 4 Schematic of multi-target co-deposition for HEAs.

[59]. Thus, compared to conventional alloys, the as-cast samples of HEAs may have obvious casting defects, such as cracks, pores, and residual stresses along with compositional gradients and abnormal grain-size distributions. In order to obtain organized and well-behaved HEAs, subsequent processing is essential [60-63].

As the development of HEAs, the elements with FCC or BCC crystalline structures were generally considered as the matrix elements. Thereafter, appropriate modification elements were added to improve the required performances. The "trial and error" traditional alloying method leads to the consumption of a large number of human and material resources, research-cycle extension, low efficiency, etc. These shortcomings are more conspicuous for multi-element HEAs [64]. The development of highthroughput experiments can well solve these problems [65]. High-throughput experiments have been developed in the preparation of thin films and bulk alloys, especially for the fabrication of thin films. In addition, the multitarget co-deposition method is suitable for the preparation of HEA films with various constituent elements [66]. As shown in Fig. 4, co-deposition uses a different distance between the substrate and the target, and different targets provide a certain concentration gradient on the substrate during deposition to produce a HEA film with a con- 
tinuous concentration gradient [66]. Subsequently, combining with high-throughput characterization techniques, we can achieve rapid screening of HEAs, and then the bulk-like selected components are prepared. According to the composition design of HEAs, many single-element or alloy targets can be prepared, with the atomic percentages of elements controlled by adjusting the target sputtering power. The HEA film with a continuous composition gradient is obtained and then the bulk-like selected alloy can be manufactured. Nowadays, the high-throughput highway to the computational HEAs design is a great opportunity and challenge for the development of HEAs [67].

\section{PHASE FORMATION}

Although there are more than four or five elements in HEAs [20], they tend to form a relatively-simple phase after solidification, such as FCC [21], BCC, or HCP $[23,68]$ structures. However, with the extensive and deep research on HEAs, it is found that the alloys also contain ordered intermetallics, amorphous and nanocrystalline precipitates $[19,47,69]$.

\section{Simple solid-solution structure in an HEA}

HEAs are easy to form phase structures with simple FCC, BCC and HCP solid-solution structures $[9,20,23]$. One famous HEA is the Cantor alloy [20], containing $\mathrm{Fe}$ (BCC), Co (HCP), Cr (BCC), Mn (BCC), and Ni (FCC) in an equimolar ratio, with only an FCC solid-solution phase when solidified dendritically in the as-cast sample. Then the 5-component alloy was expanded to a 6component alloy by adding $\mathrm{Cu}$ (FCC), $\mathrm{Nb}$ (FCC), or $\mathrm{V}$ (BCC), showing the simple FCC solid-solution structure in the as-cast alloy with different lattice parameters. When the HCP-type Ti was added, a BCC structure formed within the FCC solid-solution phase [16]. Another typical example is the $\mathrm{Al}_{x} \mathrm{CoCrFeNi}$ (molar percentage, $0 \leq x \leq 2$ ) system prepared by arc melting [70]. The as-cast CoCrFeNi alloy has a pure FCC solid-solution phase. As increasing the $\mathrm{Al}$ molar percentage from 0 to 2, the $\mathrm{Al}_{x} \mathrm{CoCrFeNi}$ system changes the crystal structure from FCC to FCC+BCC phases, and finally to a single BCC phase [55]. A typical alloy TaNbHfZr has a solely BCC structure [71].

Although the HCP phase is often referred to as a typical simple solid-solution structure of HEAs, there is few discovery for this phase. Tsau [72] found the HCP solidsolution phase in the alloy of TiCrZrNb (in atomic proportion), but the HCP phase did not exist independently, and it was in the interdendritic region, and the matrix
Table 1 Mixing enthalpy data $\left(\mathrm{kJ} \mathrm{mol}^{-1}\right)$ between the elements of $\mathrm{Fe}$, $\mathrm{Ni}, \mathrm{Cr}, \mathrm{Cu}$, and $\mathrm{Zr}$

\begin{tabular}{cccccc}
\hline & $\mathrm{Fe}$ & $\mathrm{Ni}$ & $\mathrm{Cr}$ & $\mathrm{Cu}$ & $\mathrm{Zr}$ \\
\hline $\mathrm{Fe}$ & - & -2 & -1 & 13 & -25 \\
$\mathrm{Ni}$ & - & - & -7 & 4 & -49 \\
$\mathrm{Cr}$ & - & - & - & 12 & -12 \\
$\mathrm{Cu}$ & - & - & - & - & -23 \\
$\mathrm{Zr}$ & - & - & - & - & - \\
\hline
\end{tabular}

was BCC phase. In addition, Qiao et al. [23] found that the as-cast alloy GdHoLaTbY (in atomic proportion) formed an HCP phase.

\section{Mesophase and other complex phases in HEAs}

The high entropy of HEAs hinders the formation of intermetallic compounds and the occurrence of phase separation, therefore the formation of solid-solution phases is promoted [52]. However, there are many factors that affect the formation of HEAs, including the mixed enthalpy, atomic-size difference, valence-electron concentration, and so on [50]. The mesophase or complex multi-phase coexistence forms in HEAs due to the existences of some chemically-compatible elements. Li et al. [73] studied the alloy of FeNiCrCuZr. They found that apart from the BCC phase, intermetallic compounds also precipitated in the alloy; and the formation of intermetallic compounds was due to the strong compoundformation tendency of $\mathrm{Zr}$ with other metals, consistent with measurements that the mixing enthalpies between $\mathrm{Zr}$ and other metals are too negative (Table 1). Thus, the mixing enthalpy became another dominant factor to facilitate the formation of intermetallic compounds in $\mathrm{Fe}$ $\mathrm{NiCrCuZr}$. In some systems, the high mixing entropy cannot completely overcome the contribution of the high enthalpy of mixing to the free energy.

\section{Nanocrystalline and amorphous phases in HEAs}

Conventional alloys or bulk amorphous alloys can only precipitate nanocrystals under special heat-treatment conditions. The lattice-distortion effect and the slowdiffusion effect in HEAs seriously hinder the nucleation and growth of the grains. Hence, some HEAs precipitate nanometer phase and even amorphous phase during the as-cast or complete-tempering condition $[20,40,47]$. As illustrated in Fig. 5, a series of heat-treatment conditions were performed on $\mathrm{Al}_{0.5} \mathrm{CoCrFeNi}$ alloy [74], and the bright-field image of the acicular precipitate and the corresponding diffraction patterns are present, indicating that such precipitates have the same BCC (B2) phase as 


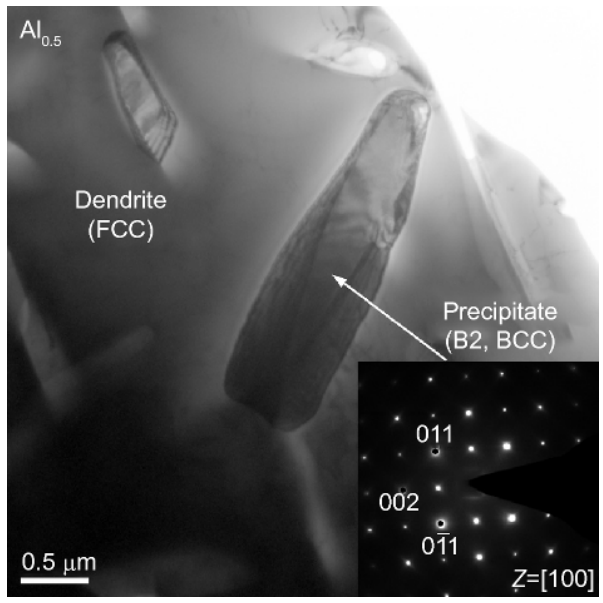

Figure 5 The bright-field image and corresponding diffraction pattern of the acicular precipitate in the $\mathrm{Al}_{0.5} \mathrm{CoCrFeNi}$ alloy (the precipitate possesses an ordered BCC crystal structure). Reproduced with the permission from Ref. [74]. Copyright 2014, Elsevier.

the interdendritic structure. Zhao et al. [75] developed an amorphous alloy, which can be uniformly deformed without generating shear at room temperature. Meanwhile, its critical size is greater than $3 \mathrm{~mm}$, and the amorphous transition temperature of the alloy is close to room temperature, with low density, high specific strength, and low elastic modulus.

\section{MICROSTRUCTURES}

In the case of multicomponent alloys, there are more chances of segregation of elements due to the difference between the constituent elements in melting points, densities, and other physical properties. Depending on the growth conditions, grains may grow into planar, cellular, or dendritic morphologies [76]. For HEAs, arc melting limits the fabrication of HEA ingots, compared to induction melting. The melting furnace with non-consumable tungsten electrode is only useful for making ingots with a limited size and shape (button shaped or slender-rod shaped as shown in Fig. 6). After the arc melting or induction melting, the alloy exhibits as-cast dendrites. The dendrites and inter-dendrites have significant component segregations [40]. Solidification/ cooling rates have a significant influence on the microstructural evolution of as-cast HEAs [77]. The AlCoCr$\mathrm{CuFeNi}$ HEA fabricated by splat quenching with rapid solidification rate $\left(10^{6}-10^{7} \mathrm{~K} \mathrm{~s}^{-1}\right)$ possessed a single BCC phase with fine polycrystalline structures, whereas the ascast alloy had multi-phases with serious inter-dendritic segregation [78].

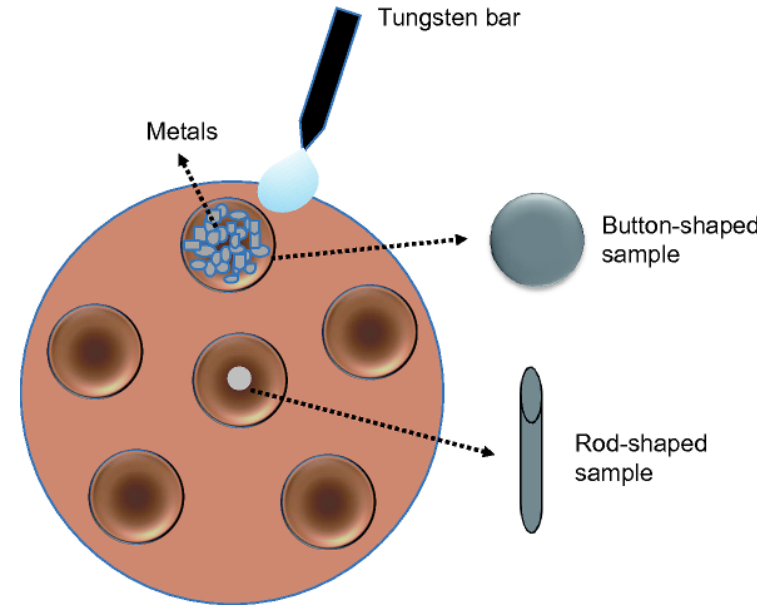

Figure 6 Schematic of arc melting.

The microstructure of the alloy can also be changed by controlling the growth direction and the growth rate of crystal during the solidification process of the alloy. Zhang et al. [79] successfully prepared $\mathrm{Al}_{0.3} \mathrm{CrFeNiCo}$ columnar crystals by Bridgman primary and secondary directional solidification. The effects of directional solidification on the microstructure, crystal orientation, and mechanical properties of the $\mathrm{Al}_{0.3} \mathrm{CrFeNiCu}_{2}$ alloy were studied. In addition, eutectic and peritectic structures can be observed in HEAs of different systems. For example, $\mathrm{Al}_{x} \mathrm{CrCeFeNi}_{2}$ HEAs exhibit eutectic clusters similar to sunflower shapes [80], while $\mathrm{AlCoCrFeNb}_{0.5} \mathrm{Ni}$ [81] and $\mathrm{CoFeNi} \mathrm{V}_{0.5} \mathrm{Nb}_{0.75}$ [58] alloys exhibit lamellar eutectic structures.

\section{PROPERTIES}

\section{Hardness}

HEA is widely studied not only because it forms a unique multi-component solid-solution phase but also because it possesses high hardness and strength. Fig. 7 shows the hardness of a variety of alloys in the as-cast and fullyannealed states. Compared with other traditional alloys, such as the 316 stainless steel, Hastelloy, HEAs have higher hardness and better anti-annealing softening performance [17].

\section{Compressive property}

The mechanical properties of HEAs are evaluated by compressive loading on the cylindrical samples $[82,83]$, which could be prepared easily by arc melting. The HEA systems generally possess an FCC phase and have great 


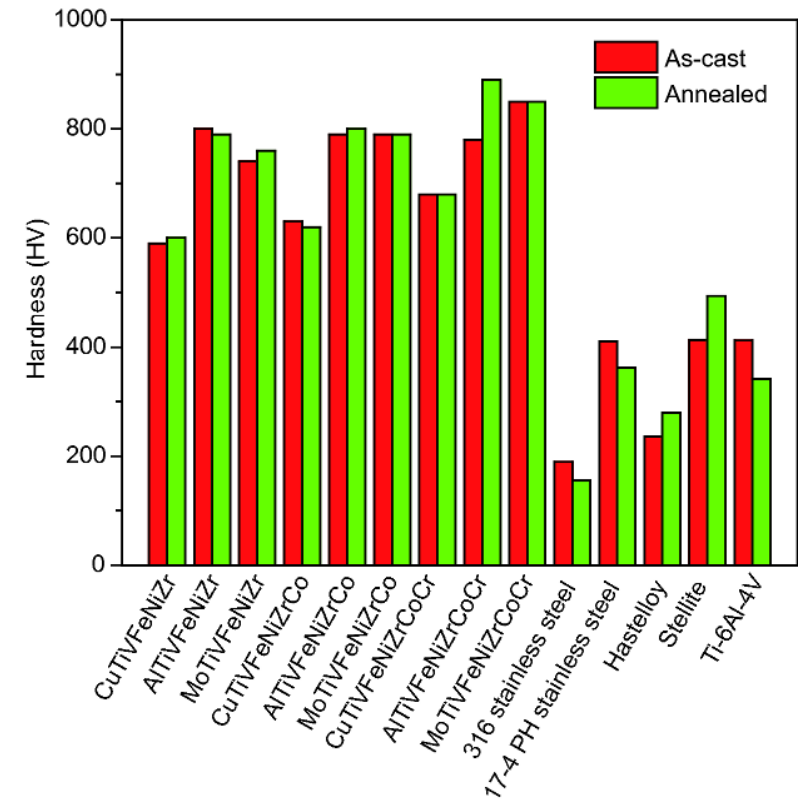

Figure 7 Comparison of hardness between HEAs and conventional alloys before and after annealing. The data are from Ref. [17].

combination of strength and ductility in compression, when compared to those with a BCC phase, in Fig. 8a. However, the yield strength of HEAs with a BCC phase is very high and comparable to bulk metallic glasses [46]. With increasing number of principal elements, the strength of the HEAs system increases due to solidsolution hardening, with reduced ductility [20]. Miracle and Senkov [19] reviewed the compression yield stresses between the refractory HEAs and other elevated-temperature alloys. The compression yield stress reduces with increasing temperature, and the inflection point is around $1,000 \mathrm{~K}$ for almost all alloys. However, NbMoTaW and NbMoTaWV exhibit outstanding behaviour and remain useful strengths up to 2,000 K (Fig. 8b).

For the $\mathrm{Al}_{x} \mathrm{CoCrFeNi}$ and $\mathrm{Al}_{x} \mathrm{CoCrCuFeNi}$ systems $[17,70]$, increasing the amount of $\mathrm{Al}$ results in the formation of a BCC phase in the FCC matrix, which yields an increase in the compressive strength at the expense of ductility. The HEAs with an FCC phase, such as $\mathrm{Al}_{0.1} \mathrm{CoCrFeNi}$ [84], CoCrFeNi, and CoCrFeNiMn [85], exhibits excellent plasticity and work-hardening behaviour with low yield strength under compressive loading. The $\mathrm{Al}_{0.75} \mathrm{CoCrFeNi}$ alloy with $\mathrm{FCC}+\mathrm{BCC}$ dual phases exhibits an excellent yield and ultimate strengths of 1,938 MPa and 2,221 MPa, respectively, but a limited ductility of $7.6 \%[86]$.

\section{Tensile property}

Few studies were focused on the tensile properties of HEAs. The crystal structure of the HEAs has a large influence on the tensile properties [36].

He et al. [87] conducted a systematic study on the influence of the progressive addition of $\mathrm{Al}$ on the mechanical behaviour of the FCC-phase CoCrFeNiMn HEA, illustrated in Fig. 9. The FCC alloy of $\mathrm{Al}_{x} \mathrm{CoCrFeNiMn}$ system exhibits excellent plasticity and low strength, whereas the dual phase alloys exhibit a better combination of strength and ductility. The $\mathrm{AlCoCrFeNi}_{2.1}$ alloy with dual phases also presents promising tensile properties with an elongation and fracture strength of $23 \%$ and 1,200 MPa, respectively [88].

In the range of low-temperature to room-temperature, the yield strength and the deformation of the alloy de-
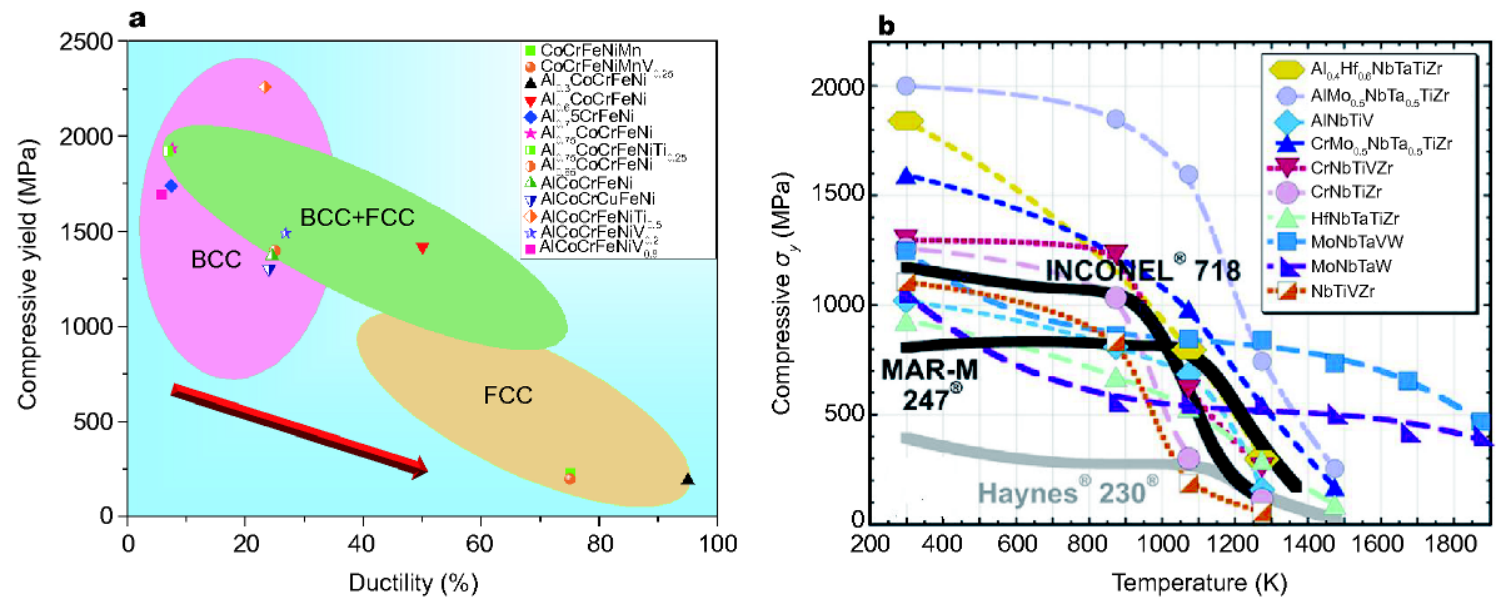

Figure 8 (a) Compressive behaviour of various HEAs; (b) compressive yield strength versus temperature. Reproduced with the permission from Ref. [19]. Copyright 2017, Elsevier. 


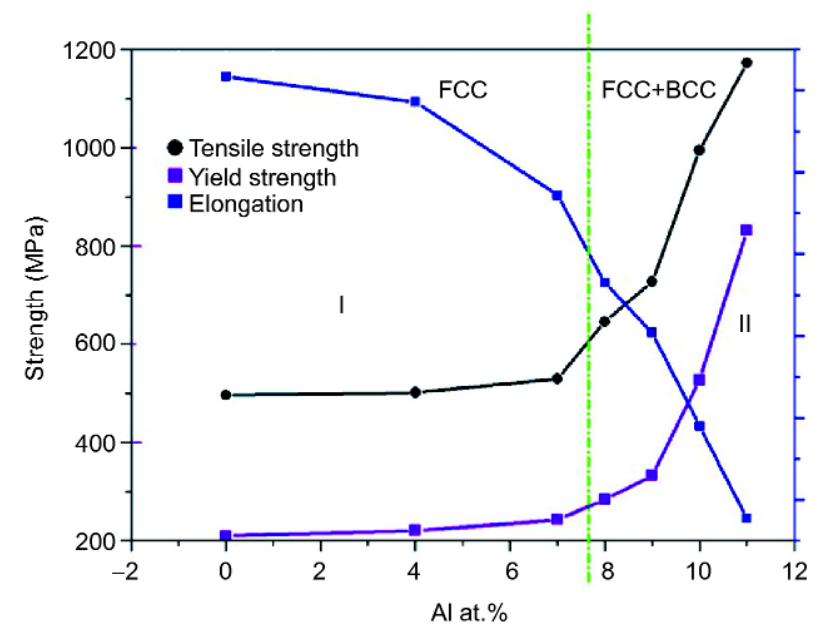

Figure 9 Tensile strength, yield strength, and elongation of the as-cast $\mathrm{Al}_{x} \mathrm{CoCrFeNiMn}$ alloys. Reproduced with the permission from Ref. [87]. Copyright 2014, Elsevier.

crease as the temperature drops. However, Li et al. [36] found that the $\mathrm{Al}_{0.3} \mathrm{CoCrFeNi}$ alloy's tensile strength and elongation in the liquid nitrogen temperature reached the maximum. The curves of the quasi-static tensile engineering of the alloy in the range of 77-298 $\mathrm{K}$ are shown in Fig. 10. The $\mathrm{Al}_{0.3} \mathrm{CoCrFeNi}$ HEA at low temperature has good plastic-deformation behavior for the formation of deformation twins, which is similar to the alloy of CoCrFeMnNi studied by Otto et al. [62]. The yield strength and shaping deformation were measured in the range of $77-1,073 \mathrm{~K}$. At the liquid-nitrogen temperature, the yield strength reaches the maximum, indicating that the alloy with a fine grain structure has very good mechanical properties over the entire testing temperatures, similar to conventional alloys, and exhibits serrated flows at intermediate temperatures. Diao et al. [45] summarized the yield strength of HEAs and conventional alloys from room temperature to $1,900 \mathrm{~K}$. The excellent mechanical properties of HEAs over a wide range of temperatures under tensile loading is evident, promising them ideal candidates for structural applications, compared to conventional superalloys and stainless steels $[45,62,89,90]$.

\section{Corrosion resistance}

Under high concentrations of sulfuric acid, hydrochloric acid, nitric acid and other corrosive solution condition, HEAs show excellent corrosion resistance, especially the one with $\mathrm{Cu}, \mathrm{Ti}, \mathrm{Cr}, \mathrm{Ni}$, or $\mathrm{Co}[43,91,92]$. Some HEAs present outstanding corrosion resistance even better than the traditional stainless steel. The $\mathrm{CoCrFeNiCu}$. HEA system shows that the $\mathrm{CoCrFeNi}$ alloy has good pitting
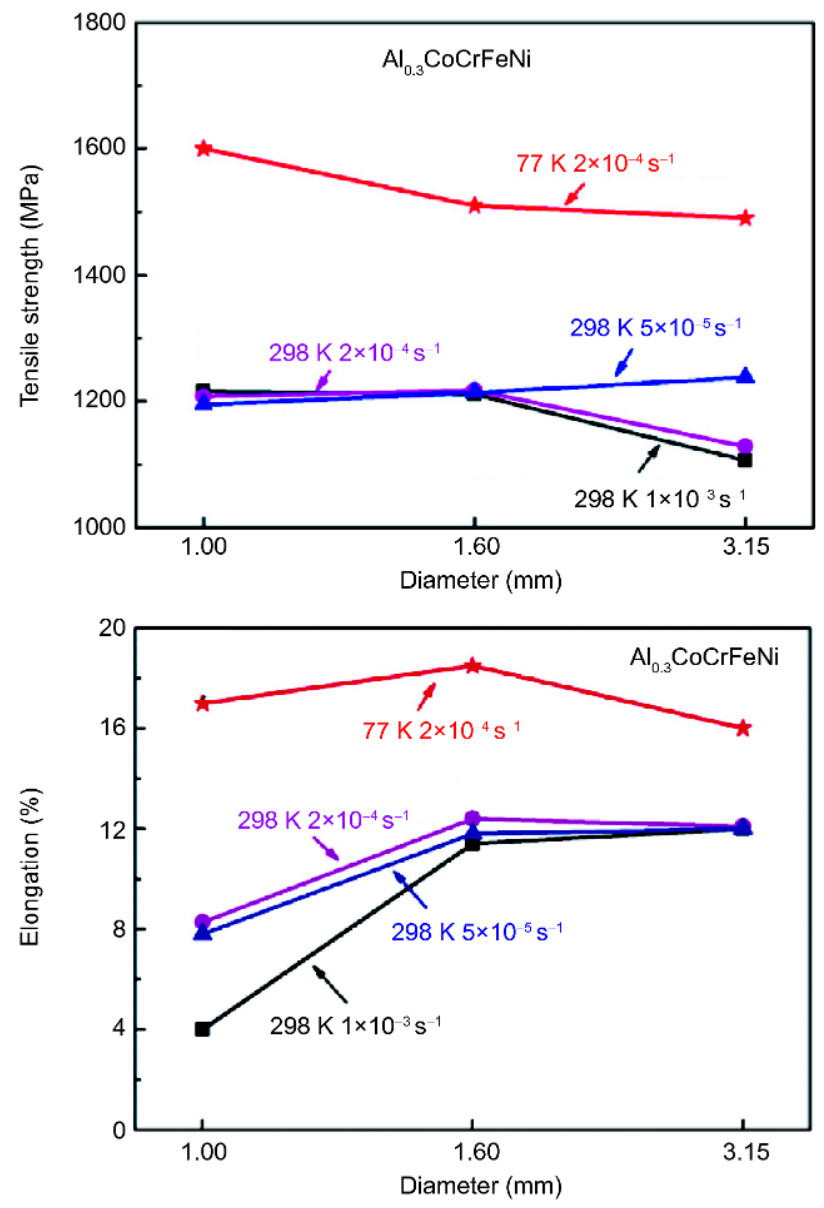

Figure 10 Tensile strength (a) and elongation (b) as a function of fiber diameter, respectively. Reproduced with the permission from Ref. [36]. Copyright 2017, Elsevier.

corrosion resistance, similar to 304 stainless steel $[43,91-$ 93]. The polarization curves of the $\mathrm{Al}_{0.5} \mathrm{CoCrCuFeNi}$ alloy and 304 stainless steel in $1 \mathrm{~mol} \mathrm{~L}^{-1} \mathrm{H}_{2} \mathrm{SO}_{4}$ solution showed that the corrosion potential of HEAs is higher, with better corrosion resistance [43,91-94].

The relationship between pitting potential $\left(E_{\mathrm{p}}\right)$ and corrosion current densities $\left(I_{\text {corr }}\right)$ of HEAs $\left(\mathrm{Al}_{x} \mathrm{CoCrFeNi}\right.$ in which $x=0.3,0.5$, and 0.7 ) and conventional alloys (such as stainless steels, Al-, Ti-, $\mathrm{Cu}-$, and Ni-based alloys) [91] are displayed in Fig. 11. The data were measured in the environment of $3.5 \mathrm{wt} \% \mathrm{NaCl}$ solution at room temperature. It suggests that HEAs have higher $E_{\mathrm{p}}$ and lower $I_{\text {corr }}$ than Al-, $\mathrm{Cu}$-, and some of Ti-based alloys. Therefore, the HEAs show excellent localized and general corrosion resistance.

\section{Thermal stability}

Refractory HEAs [27] are a category of emerging multi- 


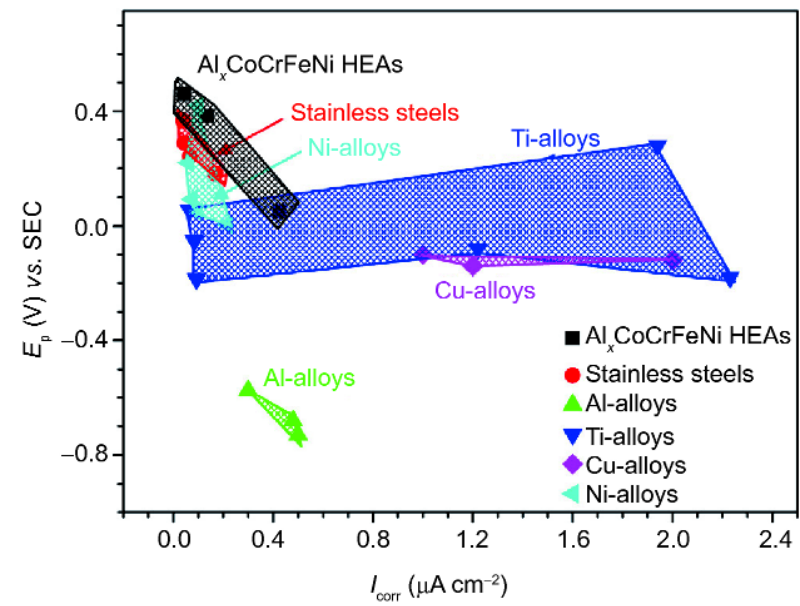

Figure 11 Comparison of $E_{\mathrm{p}}$ and $I_{\text {corr }}$ between HEAs of $\mathrm{Al}_{x} \mathrm{CoCrFeNi}$ ( $x$ $=0.3,0.5$, and 0.7 ) and other conventional alloys in $3.5 \mathrm{wt} \% \mathrm{NaCl}$ solution at room temperature. Reproduced with the permission from Ref. [91]. Copyright 2017, Elsevier.

component alloys, showing superior mechanical properties at elevated temperatures which is important for application [33,95]. The NbMoTaW alloy has better performance retention than the refractory metal tungsten after a heat exposure at $1,373 \mathrm{~K}$ for 3 days [33]. Meanwhile, the HEAs with these excellent properties drive a new class of materials in nanoscale devices potentially in high-stress and elevated-temperature applications. Sathiyamoorthi et al. [96] found that ultrafine-grained CoCrFeNi HEAs show the exceptional thermal stability upon the exposure of sintered compacts to high temperature (973 to $1,173 \mathrm{~K}$ ) and prolonged duration of $600 \mathrm{~h}$, as illustrated in Fig. 12. Samples exposed to $973 \mathrm{~K}$ for $600 \mathrm{~h}$ show negligible change in hardness. Meanwhile, the fractional decrease in hardness after $600 \mathrm{~h}$ at $1,073 \mathrm{~K}$ and $1,173 \mathrm{~K}$ is $9.5 \%$, and $25 \%$, respectively.

\section{Irradiation property}

In general, the interaction between energetic ions and atoms in the material causes lattice damage, resulting in a variety of defects, including point defects, dislocation loops and holes [97], etc. The research shows that the HEA still has high phase stability, even with the Au ionirradiation dose exceeding $50 \mathrm{dpa}$ (displacement per atom). At the same irradiation dose (50-70 dpa), compared to other commonly-used irradiation-resistant materials, such as M316 stainless steel and pure $\mathrm{Zr}$, an HEA has a relatively-low volume swelling rate [98]. Nagase et al. [99] studied the in situ electron irradiation of $\mathrm{ZrHfNb}$ with an amorphous structure, and Jin et al. [100] studied
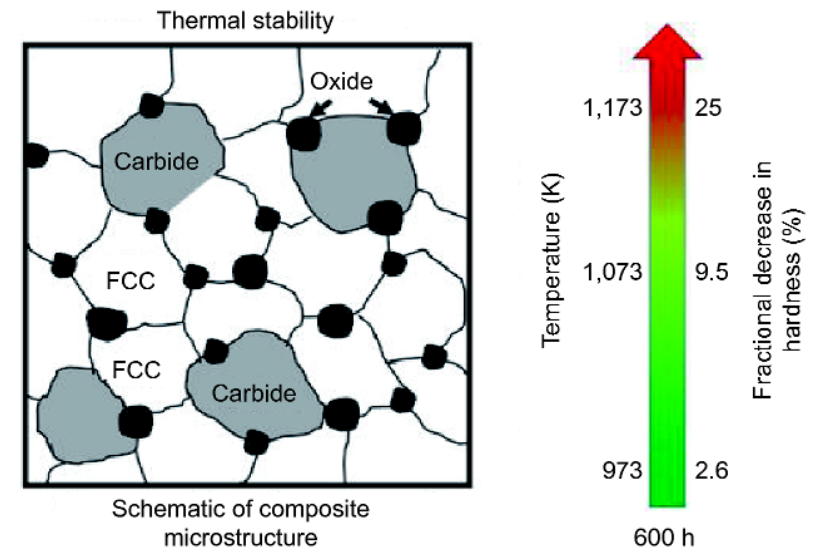

Figure 12 Diagram of composite microstructures observed in the assintered condition. Reproduced with the permission from Ref. [96]. Copyright 2017, Elsevier.

the CoCrFeNiMn with an FCC structure. It was found that the CoCrFeNiMn HEA did not change significantly after $773 \mathrm{~K}$ high-temperature and $3 \mathrm{MeV} \mathrm{Ni}$ ions irradiation, and the grains did not coarsen. High performance of HEA radiation-resistant materials provides a new idea for nuclear materials, and it has been used as the catalyst in the nuclear energy [97,101-103]. Waseem et al. [68] considered that the $\mathrm{W}_{x}$ TaTiVCr as low/reduced-activation alloys have a promising future for fusion power plants.

\section{Thermoelectric property}

Thermoelectric materials capable of the direct conversion between heat and electricity have attracted tremendous attention in the past several decades for the engine-waste heat recovery to improve the fuel efficiency. HEAs have a high degree of chaos in its atomic arrangement, resulting in the enhanced scattering of phonon and effectively reducing its lattice thermal conductivity. The PbSnTeSe [104] HEA was discovered, possessing a quite low lattice thermal conductivity of $0.6 \mathrm{~W} \mathrm{~m}^{-1} \mathrm{~K}^{-1}$ at room temperature. By minor additions of $\mathrm{La}$ to substitute $\mathrm{Pb}$, the thermoelectric performance of PbSnTeSe could be further enhanced, as indicated in Fig. 13a. The series of $\mathrm{Pb}_{1-x} \mathrm{SnTeSeLa}_{x}$ alloys containing various miscellaneous contents of La, $x=0,0.02,0.04,0.06,0.08$, and 0.10 , are designated hence as base, $0.5 \mathrm{La}, 1.0 \mathrm{La}, 1.5 \mathrm{La}, 2.0 \mathrm{La}$, and 2.5La, respectively. The $\mathrm{Pb}_{1-x} \mathrm{SnTeSeLa}_{x}$ alloys show a lattice thermal conductivity below $1 \mathrm{~W} \mathrm{~m}^{-1} \mathrm{~K}^{-1}$ at room temperature, which is far lower than that of binary compounds with the same crystal structure, for example, $\mathrm{SnTe}, \mathrm{PbTe}$, and $\mathrm{PbSe}$, due to the strong phonon scattering resulted from the severe lattice-distortion of the 

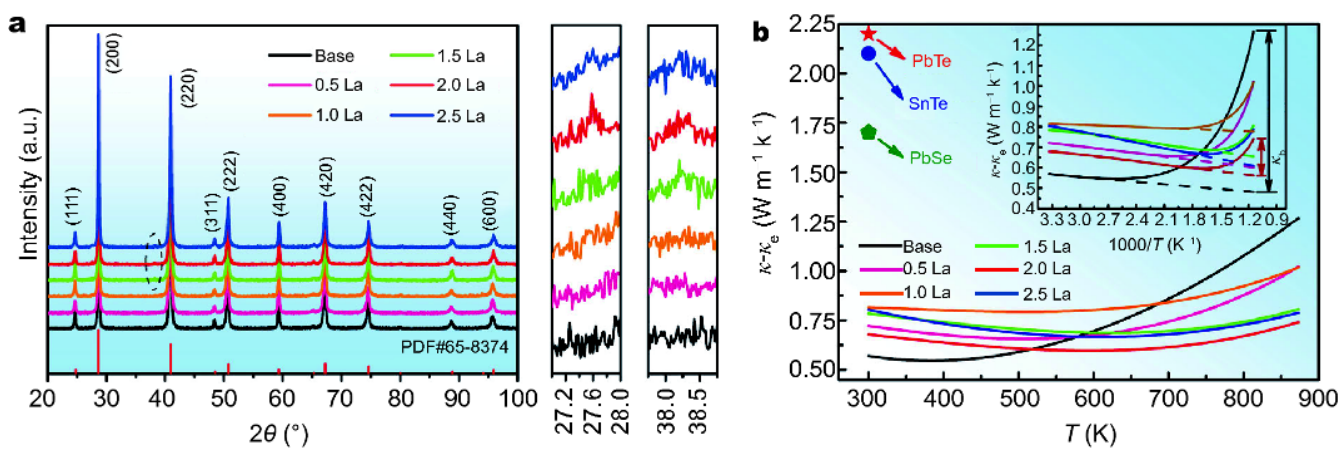

Figure 13 (a) XRD patterns of $\mathrm{Pb}_{1-x} \mathrm{SnTeSeLa}_{x}$ HEAs; (b) the combined lattice and bipolar thermal conductivity for all the samples. The lattice thermal conductivity of $\mathrm{PbTe}, \mathrm{PbSe}$, and $\mathrm{SnTe}$ at room temperature is also shown in (b). The inset in (b) presents $\kappa-\kappa_{\mathrm{e}}$ as a function of $1,000 / T$. Reproduced with the permission from Ref. [104]. Copyright 2017, Taylor \& Francis Group.

PbSnTeSe HEA. Unfortunately, the lattice thermal conductivity of the base alloy starts to rise when the testing temperature exceeds $400 \mathrm{~K}$ due to the strong bipolar effect. For all the La-doped alloys, the bipolar effect is suppressed to a certain degree but still exists. The inset of Fig. 13b analyzes the lattice thermal conductivity without bipolar contribution, $\kappa^{-} \kappa_{\mathrm{e}}$ vs. $1,000 / T$ ( $\kappa$ : thermal conductivity, $\kappa_{\mathrm{e}}$ : electronic thermal conductivity). It is obvious that the lattice thermal conductivity at $873 \mathrm{~K}$ would be lower than $0.5 \mathrm{~W} \mathrm{~m}^{-1} \mathrm{~K}^{-1}$ for the base alloy, if the bipolar effect was entirely eliminated.

HEAs also have other excellent properties, such as excellent wear resistance [105], fracture toughness [36], as well as very high resistivity $[56,106]$. At the same time, the HEA has good soft magnetic properties [20,107]. For the FeCoNi $(\mathrm{AlSi})_{0.2}$ HEA [106] prepared by arc-melting method, the saturated magnetic strength, coercivity, and electrical resistivity at room temperature reach $1.15 \mathrm{~T}$, $1,400 \mathrm{~A} \mathrm{~m}^{-1}$ and $69.5 \mathrm{~m} \Omega \mathrm{cm}^{-1}$, which are promising in the high-frequency communication.

\section{HEAs AND “MATERIALS GENOME INITIATIVE"}

The purpose of the "Materials Genome Initiative" is to increase the speed of discovery, development, production, and application of new materials by means of calculations, database and experimentation, which changes the experiment-oriented "trial and error" research and design model [108]. Therefore, HEAs as a typical new material can meet its opportunity to develop rapidly in the subsequent days. The project emphasizes a change in the research and design culture of materials through the integration of the computational and experimental data, and the integration of high-throughput computations and multi-scale simulations to accelerate material-develop- ment methods and approaches [109,110]. The material simulation is widely used to predict material properties. It can be used to simulate the material from different scales, and qualitatively and/or quantitatively describe the characteristics of materials, and promote us to understand the material from multiple angles. Fig. 14 displays the relationship between the time and space. Computational materials science involves all aspects of the material, such as different levels of structures, various properties, etc. Thus, there are many corresponding calculation methods, the first-principles density functional theory (DFT), molecular dynamics (MD), discrete dislocation dynamics (DDD), phase-field method (PFM), thermodynamics model (TM), finite element method (FEM) [111], etc. For materials with different space scales, there are corresponding material calculation methods, including the calculation of phase diagram (CALPHAD) and high-throughput methods $[26,65,69,112-117]$.

There are many formation rules and empirical criteria for HEAs, which may not apply to all HEAs. Zhang et al. [29] summarized the factors of the atomic-size difference, $\delta$, and the enthalpy of mixing, $\Delta H_{\text {mix }}$, of the multi-component alloys:

$$
\begin{gathered}
\delta=\sqrt{\sum_{i=1}^{N} x_{i}\left(1-x_{i} / \sum_{j=1}^{N} x_{j} r_{j}\right)^{2}}, \\
\Delta H_{\text {mix }}=4 \sum_{i=1, i \neq j}^{N} \Delta H_{i j}^{\text {mix }} x_{i} x_{j},
\end{gathered}
$$

where $N$ is the number of the elements in an alloy, $x_{i}$ or $x_{j}$ is the atomic percentage of the $i^{\text {th }}$ or $j^{\text {th }}$ component, $r_{j}$ is the atomic radius of the $j^{\text {th }}$ component, $\Delta H_{\text {mix }}$ is the mixing enthalpy for $\mathrm{AB}$ alloys. Subsequently, to further understand the relationship between $\Delta H_{\text {mix }}$ and $\Delta S_{\text {mix }}$, Zhang and Yang [51] proposed a new parameter, $\Omega$, defined by: 


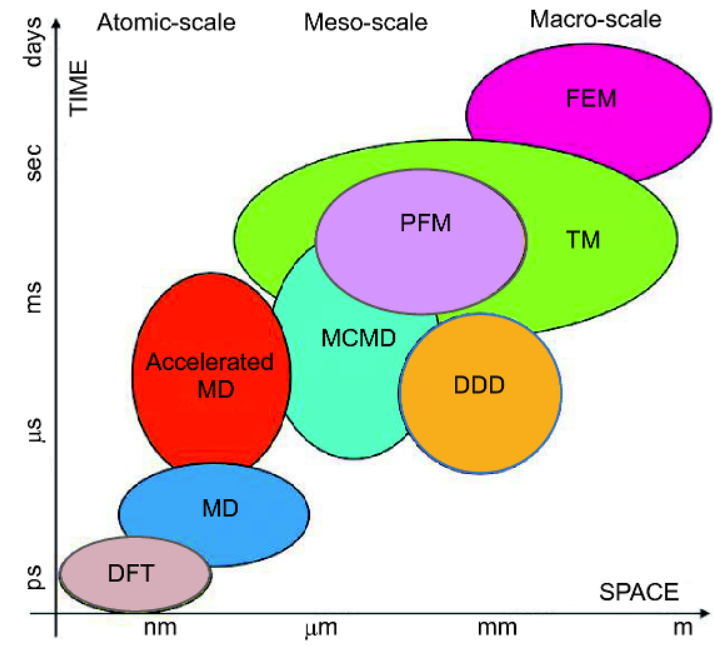

Figure 14 A map of time and spatial scales in computational materials.

$$
\Omega=\frac{T_{\mathrm{m}} \Delta S_{\mathrm{mix}}}{\left|\Delta H_{\mathrm{mix}}\right|},
$$

where $T_{\mathrm{m}}$ is the melting temperature of the $\mathrm{N}$-component alloy. Zhang et al. [40] summarized the published HEAs and suggested a phase-formation rule using the $\delta$ and $\Omega$ with $\Omega \geq 1.1$ and $\delta \leq 6.6 \%$. However, the FCC-type phase-forming $\delta$ shows a large overlap with that of the BCC-type phase, which means new rules or parameters need to be considered for the phase formation. Guo et al. [118] considered that the phase stability of FCC and BCC solid solutions could be well delineated by the valanceelectron concentration (VEC) defined by:

$$
\mathrm{VEC}=\sum_{i=1}^{N} x_{i} \mathrm{VEC}_{i},
$$

where $x_{i}$ and $\mathrm{VEC}_{i}$ is the atomic percentage and VEC of the $i^{\text {th }}$ component. The simplified rule to identify the phases of HEAs is: $\mathrm{VEC}<6.87, \mathrm{BCC}$; VEC $>8$, FCC. Although the understanding of the prediction of phase stability from fundamental properties of constituent elements benefits the alloy design greatly, and then could be used to predict the mechanical or physical properties of the alloys, the accuracy of the previous parameters are limited [118]. Thus, the computation modeling is an excellent opportunity and challenge.

The HEA is a new type of materials that exhibits a disordered structure, and the alloy generally contains at least five composition elements, and the atomic ratio of each element is above 5\% [17,20]. Such a multicomponent alloy is a vast challenge for the computational modeling [50]. However, with the research and interest in the field of HEAs, and the gigantic development of material computation, there are many calculations and pre- dictions to study the structures, properties, dynamics, and thermodynamics of HEAs [119-123].

\section{DFT computations}

Among the available predictive computing techniques, the DFT method is probably the ideal technique for solving multi-composition alloy systems $[40,112]$, such as HEAs. Generally, the first-principle calculation and modeling are the solution of the Schrödinger equation, which only requires structures and atomic numbers as the input to predict physical properties; and no experiments are needed. The following equation is the many-body Schrödinger's equation [124]:

$$
\widehat{H} \Psi(r)=E \Psi(r),
$$

where the $\widehat{H}$ is Hamiltonian operator, $\Psi(\vec{r})$ is the statewave function, and $E$ is the energy. However, the Schrödinger equation is very difficult to describe a complex system, and can only handle simple electronic systems, such as hydrogen atoms [125]. Therefore, the researchers use some methods to scientifically and rationally approximate and simplify the Schrödinger equation. The most classical method is the DFT [126]. The solution of the bulk ground state is accurately reduced to the solution of the ground density distribution, which is given by the Schrödinger equation of a single particle. Kohn and Sham [40] considered that the particle density function of a multi-particle system can be obtained by a simple single-particle wave equation, and the Kohn-Sham equation [127] is a self-consistent equation.

The DFT mainly converts the problem of multi-electrons into that of a single electron, and describes the physical properties of the ground state through the ground state electron density. The DFT calculations usually only contain the basic physical constants, such as the speed of light, Planck's constant, electronic charge, etc. as input parameters [128]. Based on the most accurate theory, the predicted results are in good agreement with the experimental results [112]. The first-principles approach referred here deals with the DFT. Although the DFT has many simplifications of the Schrödinger equation, the computational process is still challenging due to the HEAs containing multiple principal components. Thus, hybrid Monte Carlo/molecular dynamics (MC/ MD) simulations, $a b$ initio molecular dynamics (AIMD) simulations, special quasi-random structure (SQS) modeling, coherent potential approximation (CPA), even small sets of ordered structures (SSOS) calculations are used for the DFT calculation of HEAs [24,40,59,116,129135]. 
By the DFT calculations, the electron density near the Fermi surface is often used to reveal the stability of materials and some functional properties, especially the band gap, magnetic properties, etc. The element of the transitional (3d) HEAs is usually magnetic [40,44,106,128, 129,136]. The model of the transitional HEAs can be constructed by a supercell or SQS. Normally, only the spin orbit is considered or the magnetic force is not taken into account. In the DFT calculations, we need to consider the spin polarization. Zuo et al. [129] used the SQS to construct the structures of $\mathrm{CoFeMnNi}$, CoFeMnNiCr, and CoFeMnNiAl, with the DFT calculations conducted at $0 \mathrm{~K}$ through the VASP (the Vienna ab initio simulation package). The electron density of the $3 \mathrm{~d}$ HEAs with spin polarization is considered and illustrated in Fig. 15. The DFT calculations on the electronic and magnetic structures reveal that the anti-ferromagnetism of $\mathrm{Mn}$ atoms in $\mathrm{CoFeMnNi}$ is suppressed especially in the CoFeMnNiAl HEA, because $\mathrm{Al}$ changes the Fermi level and itinerant electron-spin coupling that leads to ferromagnetism.

\section{MD calculations}

The MD calculations are used for predicting the thermomechanical properties, which computes the materials from a molecular-scale and has a very extensive range of applications [137]. MD is well suited to reproduce the smart amplitude oscillations of atoms in the vicinity of crystal-lattice sites. The probability of an atom crossing the barrier from one lattice site to another is prohibitively low and will rarely occur on the MD time scale at low temperature [132]. The method mainly relies on Newtonian mechanics to simulate the motion of the molecular system. The samples are extracted from the whole system consisting of different states of the molecular system, and calculation is used to construct the configuration of the system.

Sharma et al. [24] investigated phase transformations (PTs) in $\mathrm{Al}_{x} \mathrm{CrCoFeNi}$ using classical MD simulations. The influences of cooling rates, temperature, and $\mathrm{Al}$ contents on PTs were investigated by the MD simulation and experimental method in $\mathrm{Al}_{x} \mathrm{CrCoFeNi}$ (Fig. 16). The cooling rates' effect could be neglected. Two transformations, molten/amorphous and amorphous/crystalline phases, were observed with the temperature decreased below the certain temperature. At last, the nucleation type was determined by the contents of Al. The nucleation type was the $\mathrm{Al}$ phase when $x=10$ and 20 , while the amorphous phase when $x \geq 30$, respectively. This trend was consistent with the common neighbor analysis with lower $\mathrm{Al}$ contents [24].

\section{CALPHAD modeling}

The most important tools to design HEAs are the phase diagrams and thermodynamic properties depending on the thermodynamic databases. Gao et al. $[40,44]$ summarized that the term, "thermodynamic database" , means that the parameters for the Gibbs energies of a large number of binary and ternary systems are assembled, which are important for the intended compositional ranges. Gao also gave the schematic of the CALPHAD processing and suggested that the first step in developing a thermodynamic database of a HEAs system is to collect the thermochemistry and phase-equilibrium data from the articles about the lower-order systems, generally the related binaries and/or ternaries. However, if such data are not available unfortunately, it becomes necessary to design and carry out experiments. In this regard, the thermodynamic data obtained from the DFT calculations will be useful to fill up experimental data $[31,116]$. Thus, the reliable thermodynamic databases, containing a series of functions related to the composition and temperature, are assessed by the CALPHAD method, based on the reliable experimental data and accurate DFT results [40,50,113-117,119-122].

Previously, Zhang et al. [26] studied the phase stability of $\mathrm{Al}-\mathrm{Co}-\mathrm{Cr}-\mathrm{Fe}-\mathrm{Ni} \mathrm{HEAs}$ and found that the experimental results are consistent with the CALPHAD modeling (Fig. 17). As one of the new-generation low-density structural materials for automobile and aerospace, the phase stability of Al-Co-Cr-Fe-Ni HEAs is a research focus, and the CALPHAD method proves a powerful tool to study the phase stability and transformation as well as the alloy design.

\section{High-throughput methods}

As the "Materials Genome Initiative " focuses on calculations, database, and experimentation in a three-in-one way, there are more examples of success in terms of computations and simulations as a way to speed up the material design $[69,128]$. Troparevsky et al. [112] used the high-throughput DFT to calculate the formation enthalpy between binary alloys to predict the formation of singlephase HEAs. The method correctly identifies all known single-phase alloys while getting rid of the similar elemental combinations that are known to form an alloy containing multiple phases. More importantly, they predicted plenty of potential single-phase alloy compositions and guided experimental studies. In Fig. 18, the highthroughput DFT calculation method demonstrates the higher accuracy in predicting new materials.

HEAs generally contain at least five alloying elements 

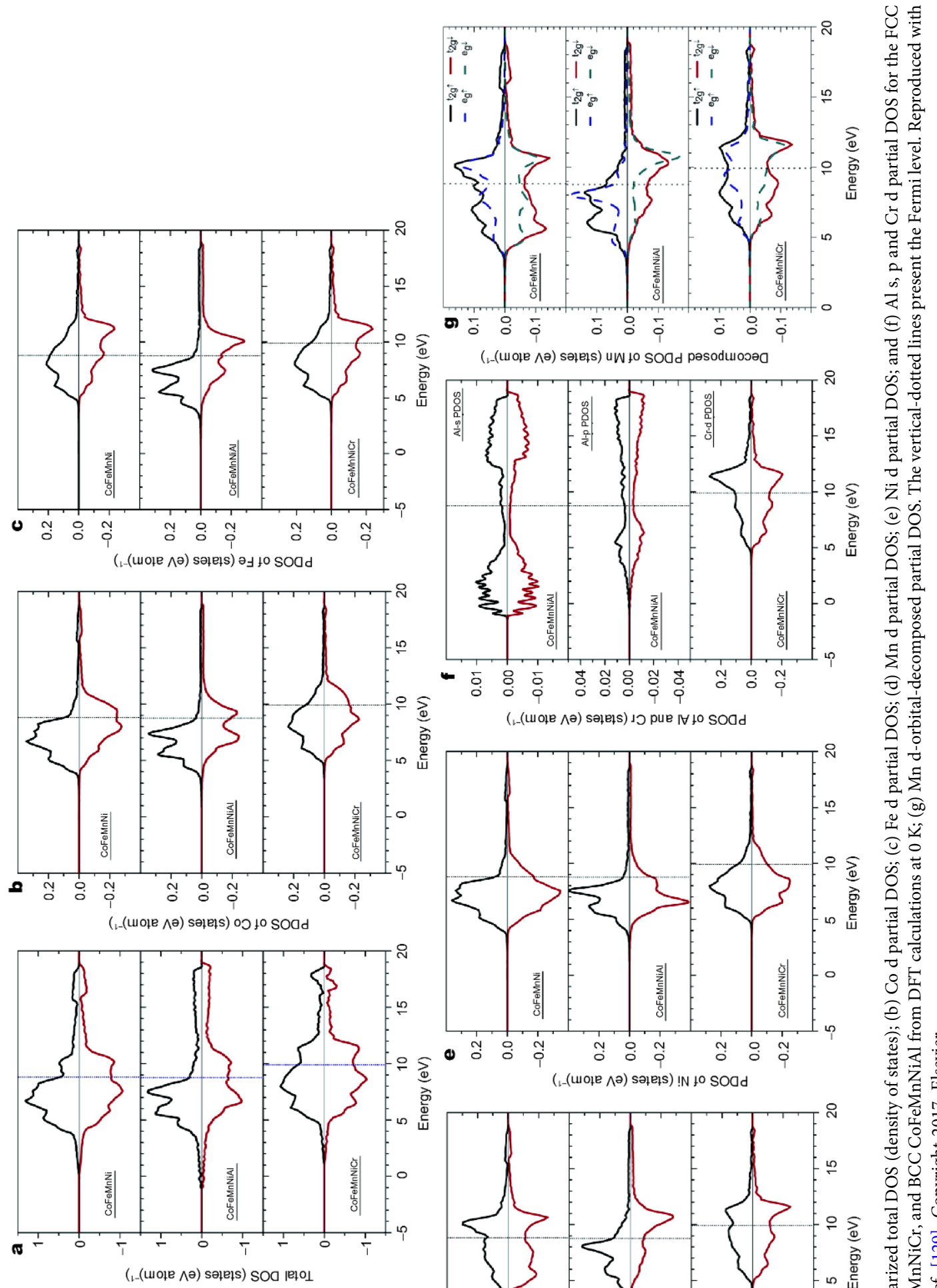

氖

它
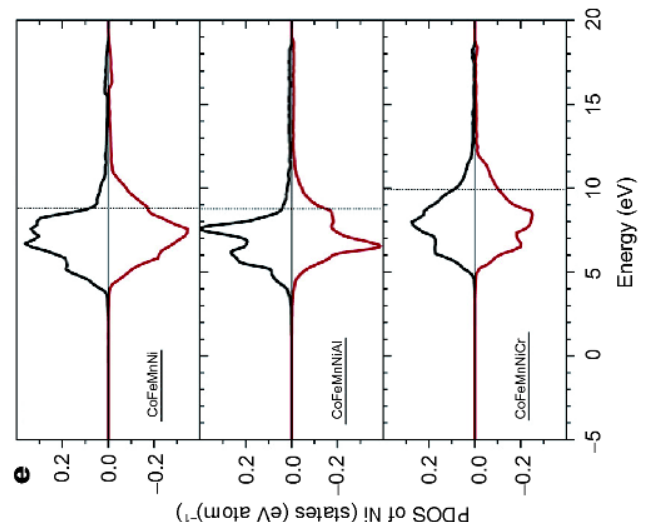

( „(- (mole $\wedge$ ә) satels) !n to sood

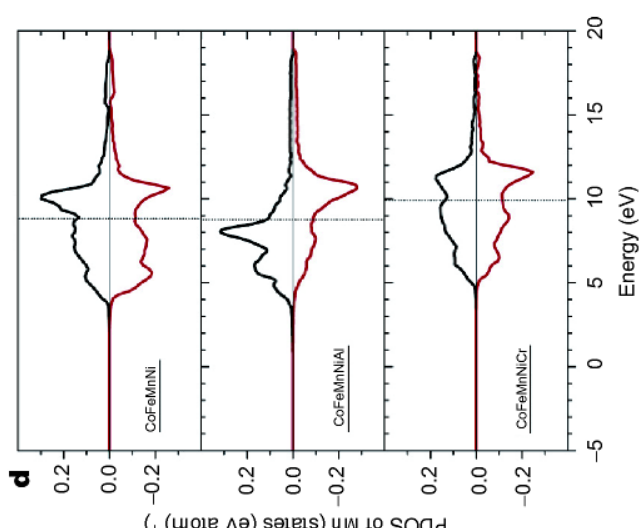

( $\left(\right.$ (urole $\left.\wedge^{\theta}\right)$ selels) uW to soad

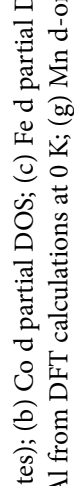



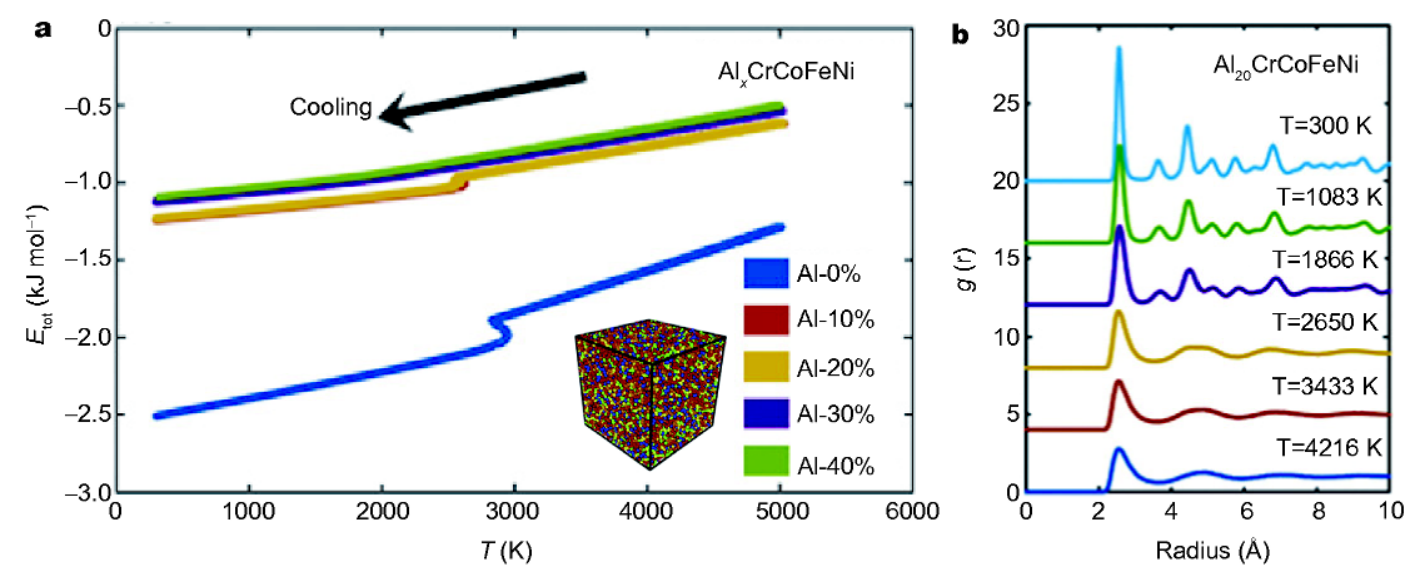

Figure 16 (a) The influence of $\mathrm{Al}$ content on phase transition via $E_{\text {tot }}-T$ (total energy per atom-temperature); (b) the phase type of nucleation via radial distribution at different temperature below 2,650 K. Reproduced with the permission from Ref. [24]. Copyright 2017, Elsevier.
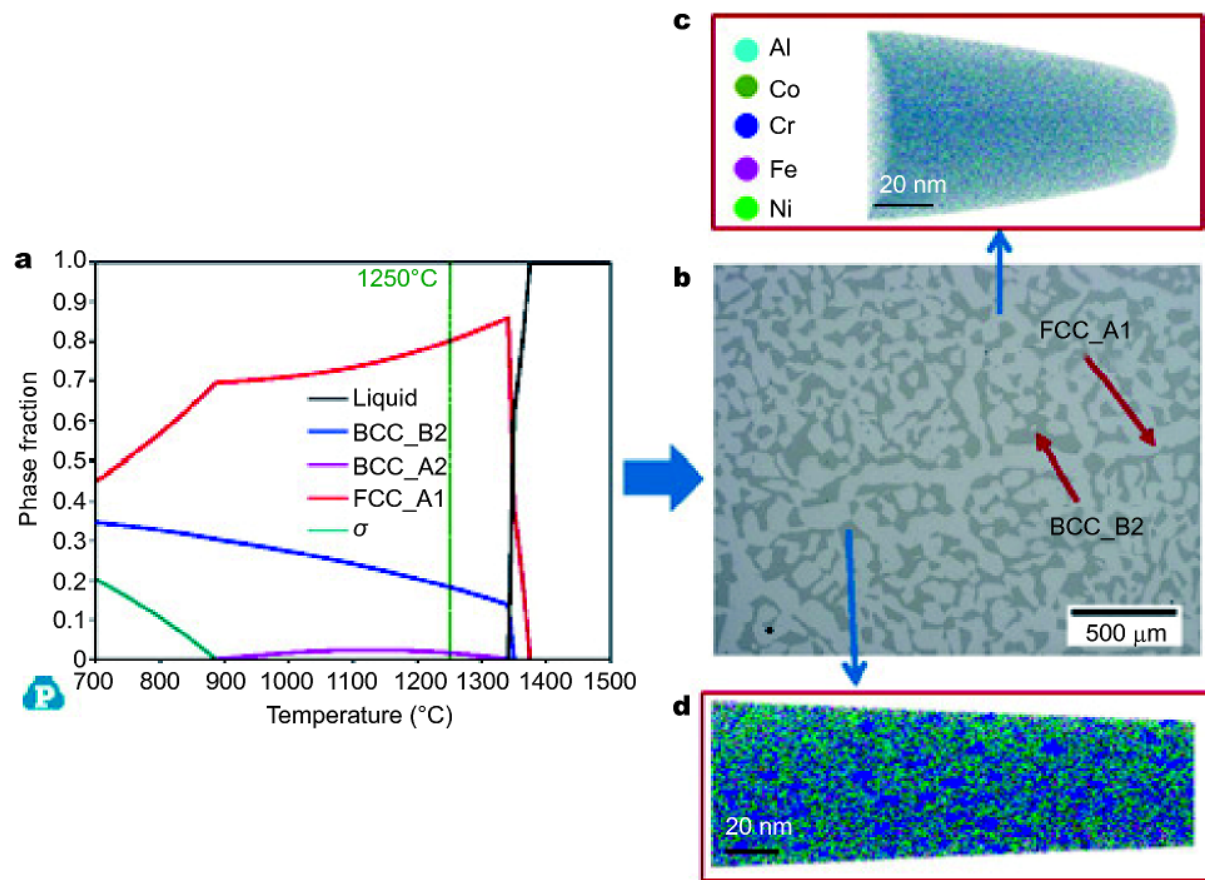

Figure 17 Comparison of the CALPHAD calculations and experimental observation of $\mathrm{Al}_{0.7} \mathrm{CoCrFeNi} \mathrm{HEA}$. (a) Equilibrium calculation; (b) opticalmicroscope image of the specimen aged at 1,523 K for 1,000 h; (c) APT result: FCC_A1; (d) APT result: BCC_A2 + BCC_B2. Reproduced with the permission from Ref. [26]. Copyright 2016, Elsevier.

and every element with high content $[20,40,45]$. Such multi-component alloys are difficult to rely on the existing binary-alloy phase diagrams or ternary-alloy phase diagrams for the material design and formation prediction. Miracle and Senkov [19] used the CALPHAD calculations to predict the phase formation of the alloy and found that phase prediction is far from the experimental results, as shown in Fig. 19. Chen et al. [138] used CALPHAD calculations combined with DFT to establish a thermodynamic database especially for HEAs within a 15-element framework applied in many groups well.

\section{FUTURE TRENDS AND PROSPECTS}

HEAs have excellent properties, such as excellent me- 


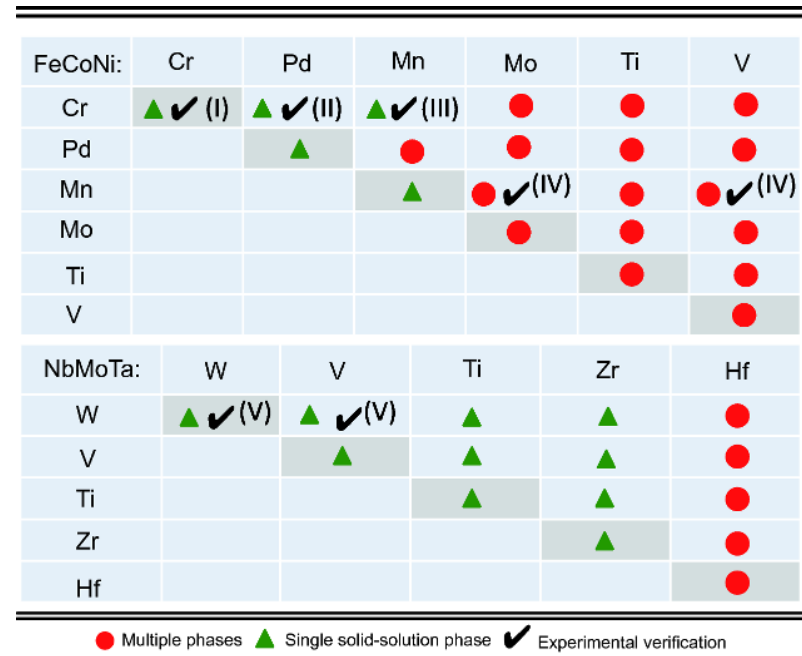

Figure 18 The predicted phase composition after one- or two- components added to FeCoNi and NbMoTa. Reproduced with the permission from Ref. [112]. Copyright 2015, the American Physical Society.

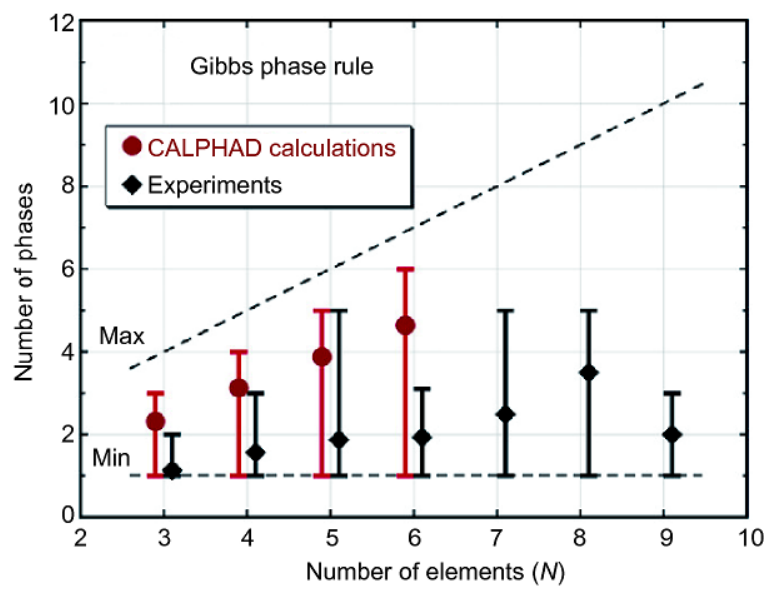

Figure 19 The number of formed phases for experiments and CALPHAD calculations. Reproduced with the permission from Ref. [19]. Copyright 2017, Elsevier.

chanical properties, high-temperature performance, as well as corrosion and irradiation resistance, which are the potential materials under extreme conditions. Although many studies focus on HEAs, our understanding of HEAs fundamental is rare. HEAs contain a variety of systems with more than five different elements in approximately equal-molar, which offer unlimited possibilities for the discovery and development of new alloys. Several future trends and prospects are proposed, based on the existing HEAs and materials-science literature, as following.

1. Among HEAs, CoCrFeMnNi [16], HfNbTaTiZr [139] and DyGdHoTbY [23] are classical representatives of the equimolar single-phase HEAs in FCC, BCC, and HCP lattice structures, respectively. The two definitions of HEAs have been described, respectively. There are two restrictions for the former one, single-phase and equal molar fraction. Therefore, searching for HEAs with single-phase solid-solution structure with more than five principal elements is a research focus for decades. With the in-depth understanding of HEAs, these two restrictions have been broken. Now, the non-equimolar complex phases (the matrix is a solid solution) HEAs have been an important part of HEAs. Therefore, HEA can be divided into the first and the second generations, as illustrated in Fig. 20 and Table 2. The research scope of HEAs expands from the central region to the surroundings, which means the development from the equimolar single-phase solid-solution alloys to the non-equimolar multi-phase solid-solution alloys, which affects the definition of HEAs and the research scope. In other words, the evolution of HEAs conception facilitates the material design and development, meanwhile extends this idea to meet the specific needs, rather than rigidly adheres to the classical high-entropy definition. The non-equimolar complex-phases HEAs can be modified in the future to improve their performance by changing the component ratio and adding minor components to maintain a certain phase in special condition, or forming a second phase for precipitation strengthening or composite strengthening, such as the TRIP (transformation-induced plasticity) HEA $\mathrm{Fe}_{50} \mathrm{Mn}_{30} \mathrm{Cr}_{10} \mathrm{Co}_{10}$ [140], the precipitation-hardening HEA [74], and eutectic HEA [90].

2. At present, the common preparation methods of HEAs are traditional arc melting and induction melting. In order to shorten the development cycle and collect numerous data via a few experiments, new preparation methods, such as 3D printing, magnetron sputtering and directional solidification, etc. are applied to the study of HEAs. And with the application of high-throughput experimental method in HEAs research [141], a series of small samples with different composition or one sample containing composition gradient were fabricated. Combing with the highly developing technology of microscopy, material properties testing and computer, a lot of data and reliable relationship between composition and properties will be got in a short time.

3. As shown in the definition of HEAs, the elemental component, phase and thermodynamic properties (entropy) play the critical role on the properties of HEAs. Therefore, compared with experimental methods to design the HEAs, the alloy designing, based on the properties calculated by the DFT or MD method and the 


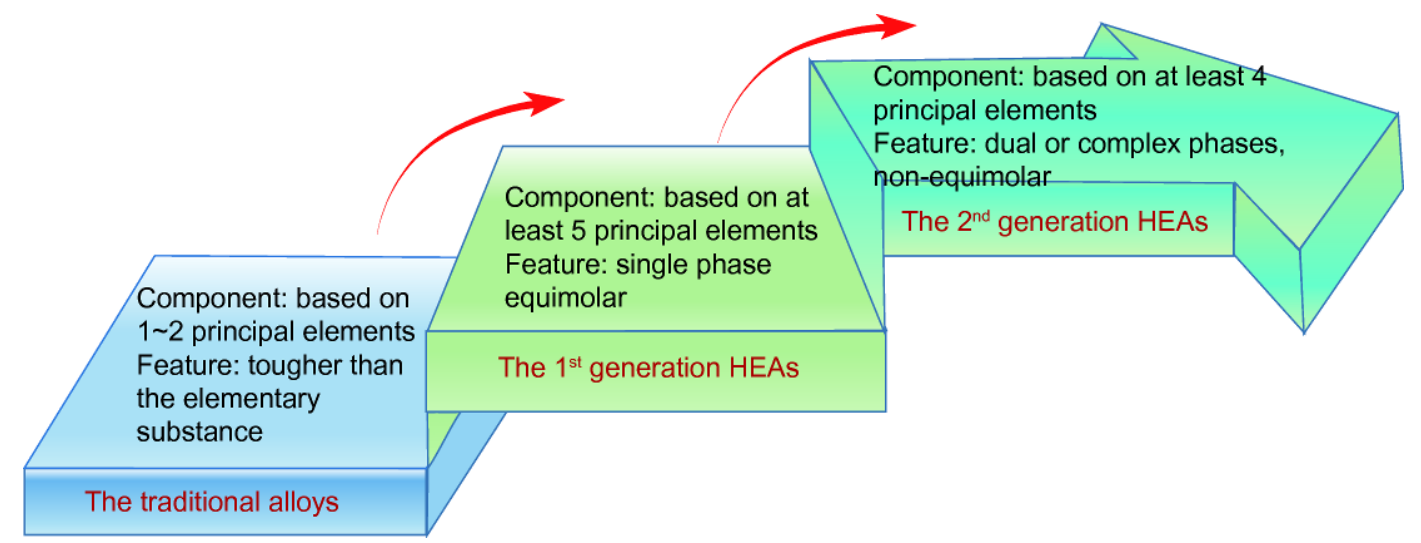

Figure 20 The evolution of alloys.

Table 2 Characteristics for the two generations of HEAs

\begin{tabular}{ccccc}
\hline Classification & Component & Feature & Composition & Atoms arrangement \\
The traditional alloys & $\begin{array}{c}1-2 \text { principal } \\
\text { elements }\end{array}$ & $\begin{array}{c}\text { Tougher than the } \\
\text { elementary substance }\end{array}$ \\
The $1^{\text {st }}$ generation HEAs & $\begin{array}{c}\text { At least } 5 \text { principal } \\
\text { elements }\end{array}$ & $\begin{array}{c}\text { Single phase, } \\
\text { equimolar }\end{array}$ & \\
The $2^{\text {nd }}$ generation HEAs & $\begin{array}{c}\text { At least } 4 \text { principal } \\
\text { elements }\end{array}$ & $\begin{array}{c}\text { Dual or complex } \\
\text { phases, non-equimolar }\end{array}$ & &
\end{tabular}

multi-component phase diagrams assessed by CALPHAD, is an effective method to save time and reduce the cost. However, the multiple elements (more than 5) and microstructures (solid solutions) of HEAs make the computational process much more complex and timeconsuming than that in conventional alloys. In addition, there is a certain gap between the phase composition of HEAs measured by the experimental method and the prediction by the CALPHAD method [69]. Therefore, it is crucial to develop reliable and robust databases for HEAs through the "Materials Genome Initiative". There is no doubt that advanced computing methodologies that can simulate the dislocation-related properties in HEAs are highly desirable nowadays.

4. There is a great opportunity for HEAs to overcome the bottlenecks of conventional alloys and to be applied in certain critical environment. For example, HEAs show great fatigue and fracture resistance [37-39], and superior high tensile strengths at cryogenic temperatures [36,39].
These outstanding properties make it possible for the HEAs to be used in turbine blades of aircraft [79], and cryogenic environments [36] as engineering alloys. HEAs possess low swelling after ion irradiation and some selfhealing effects that has good application prospect in the field of nuclear materials [142].

5. The studies of HEAs are mainly focused on the bulk alloys, but less on the high-entropy films properties of corrosion resistance, wear resistance, irradiation properties, mechanical properties, and elevated temperatures stability. High-entropy nitride films have been applied in cutting tools [143]. Another significant potential application of high-entropy films is as diffusion barriers [144]. Sheng et al. [145] proposed huge application potentials of high entropy films in the fields of solar thermal conversion systems.

6. Although massive articles focus on the mechanical behavior of HEAs, while limited work focused on the elevated-temperature mechanical properties. More me- 
chanical tests at room temperature and elevated temperatures with different strain rates should be done, which will be a precious guide to the broader application of HEAs, especially the tensile tests. Another interesting phenomenon found in the study of HEAs is that the stress-strain curve appears to be serrated in a specific temperature and strain rates range, and the occurrence of serration behavior will seriously affect the application of HEAs, because the unsmooth stress-strain curve is difficult to predict the material safety factor [146]. Serration behavior is closely related to the flow units in materials, and the flow units will change with the changes of testing temperatures and strain rates [147]. Since the serration behavior of HEAs reflects the deformation mechanism, it is necessary to study the serration behavior of HEAs more thoroughly.

Received 20 November 2017; accepted 22 December 2017; published online 2 January 2018

1 He Q, Ding Z, Ye Y, et al. Design of high-entropy alloy: a perspective from nonideal mixing. JOM, 2017, 69: 2092-2098

2 Williams J, Starke Jr. E. Progress in structural materials for aerospace systems. Acta Mater, 2003, 51: 5775-5799

3 Ezugwu E, Wang Z. Titanium alloys and their machinability-a review. J Mater Processing Tech, 1997, 68: 262-274

4 Schinhammer M, Hänzi A, Löffler J, et al. Design strategy for biodegradable Fe-based alloys for medical applications. Acta Biomater, 2010, 6: 1705-1713

5 Inoue $\mathrm{A}$, Shen $\mathrm{B}$, Chang $\mathrm{C}$. Fe- and Co-based bulk glassy alloys with ultrahigh strength of over 4,000 MPa. Intermetallics, 2006, 14: 936-944

6 Inoue $\mathrm{A}$, Zhang $\mathrm{W}$, Zhang $\mathrm{T}$, et al. High-strength Cu-based bulk glassy alloys in $\mathrm{Cu}-\mathrm{Zr}-\mathrm{Ti}$ and $\mathrm{Cu}-\mathrm{Hf}-\mathrm{Ti}$ ternary systems. Acta Mater, 2001, 49: 2645-2652

7 Gawande M, Goswami A, Felpin F-, et al. Cu and Cu-based nanoparticles: synthesis and applications in catalysis. Chem Rev, 2016, 116: 3722-3811

8 Inoue A, Kong F, Zhu S, et al. Development and applications of highly functional Al-based materials by use of metastable phases. Mat Res, 2015, 18: 1414-1425

9 Manivasagam G, Suwas S. Biodegradable Mg and Mg based alloys for biomedical implants. Mater Sci Tech, 2014, 30: 515-520

10 Abdelaziz M, Paradis M, Samuel A, et al. Effect of aluminum addition on the microstructure, tensile properties, and fractography of cast Mg-based alloys. Adv Mater Sci Eng, 2017, 2017: $1-10$

11 Geetha M, Singh A, Asokamani R, et al. Ti based biomaterials, the ultimate choice for orthopaedic implants-a review. Prog Mater Sci, 2009, 54: 397-425

12 Lee M, Lee J, Bae D, et al. A development of Ni-based alloys with enhanced plasticity. Intermetallics, 2004, 12: 1133-1137

13 Ping D, Gu Y, Cui C, et al. Grain boundary segregation in a NiFe-based (Alloy 718) superalloy. Mater Sci Eng-A, 2007, 456: 99102

14 Inoue A. Stabilization of metallic supercooled liquid and bulk amorphous alloys. Acta Mater, 2000, 48: 279-306

15 Guo S, Liu C. Phase stability in high entropy alloys: formation of solid-solution phase or amorphous phase. Prog Nat Sci-Mater Int, 2011, 21: 433-446

16 Cantor B, Chang I, Knight P, et al. Microstructural development in equiatomic multicomponent alloys. Mater Sci Eng-A, 2004, 375-377: 213-218

17 Yeh J, Chen S, Lin S, et al. Nanostructured high-entropy alloys with multiple principal elements: novel alloy design concepts and outcomes. Adv Eng Mater, 2004, 6: 299-303

18 Yeh J, Chen Y, Lin S, et al. High-entropy alloys-a new era of exploitation. MSF, 2007, 560: 1-9

19 Miracle D, Senkov O. A critical review of high entropy alloys and related concepts. Acta Mater, 2017, 122: 448-511

20 Zhang Y, Zuo T, Tang Z, et al. Microstructures and properties of high-entropy alloys. Prog Mater Sci, 2014, 61: 1-93

21 Li DY, Zhang Y. The ultrahigh charpy impact toughness of forged $\mathrm{Al}_{x} \mathrm{CoCrFeNi}$ high entropy alloys at room and cryogenic temperatures. Intermetallics, 2016, 70: 24-28

22 Li Z, Tasan C, Pradeep K, et al. A TRIP-assisted dual-phase highentropy alloy: grain size and phase fraction effects on deformation behavior. Acta Mater, 2017, 131: 323-335

23 Zhao Y, Qiao J, Ma S, et al. A hexagonal close-packed highentropy alloy: the effect of entropy. Mater Des, 2016, 96: 10-15

24 Sharma A, Deshmukh S, Liaw P, et al. Crystallization kinetics in $\mathrm{Al}_{x} \mathrm{CrCoFeNi}(0 \leq x \leq 40)$ high-entropy alloys. Scripta Mater, 2017, 141: 54-57

25 Zhang Y, Yang X, Liaw P. Alloy design and properties optimization of high-entropy alloys. JOM, 2012, 64: 830-838

26 Zhang C, Zhang F, Diao H, et al. Understanding phase stability of Al-Co-Cr-Fe-Ni high entropy alloys. Mater Des, 2016, 109: 425433

27 Senkov O, Wilks G, Miracle D, et al. Refractory high-entropy alloys. Intermetallics, 2010, 18: 1758-1765

28 Zhang Y, Zhou Y, Hui X, Wang M, Chen G. Minor alloying behavior in bulk metallic glasses and high-entropy alloys. Sci China Phys Mech Astron, 2008, 51: 427-437

29 Zhang Y, Zhou Y, Lin J, et al. Solid-solution phase formation rules for multi-component alloys. Adv Eng Mater, 2008, 10: 534538

30 Lu Z, Wang $\mathrm{H}$, Chen $\mathrm{M}$, et al. An assessment on the future development of high-entropy alloys: summary from a recent workshop. Intermetallics, 2015, 66: 67-76

31 Pickering E, Jones N. High-entropy alloys: a critical assessment of their founding principles and future prospects. Int Mater Rev, 2016, 61: 183-202

32 Chuang $\mathrm{M}$, Tsai $\mathrm{M}$, Wang $\mathrm{W}$, et al. Microstructure and wear behavior of $\mathrm{Al}_{x} \mathrm{Co}_{1.5} \mathrm{CrFeNi}_{1.5} \mathrm{Ti}_{y}$ high-entropy alloys. Acta Mater, 2011, 59: 6308-6317

33 Zou Y, Ma H, Spolenak R. Ultrastrong ductile and stable highentropy alloys at small scales. Nat Commun, 2015, 6: 7748

34 Wu Y, Cai Y, Wang T, et al. A refractory $\mathrm{Hf}_{25} \mathrm{Nb}_{25} \mathrm{Ti}_{25} \mathrm{Zr}_{25}$ highentropy alloy with excellent structural stability and tensile properties. Mater Lett, 2014, 130: 277-280

35 Deng Y, Tasan C, Pradeep K, et al. Design of a twinning-induced plasticity high entropy alloy. Acta Mater, 2015, 94: 124-133

$36 \mathrm{Li} \mathrm{D}$, Li C, Feng T, et al. High-entropy $\mathrm{Al}_{0.3} \mathrm{CoCrFeNi}$ alloy fibers with high tensile strength and ductility at ambient and cryogenic temperatures. Acta Mater, 2017, 123: 285-294

37 Gludovatz B, Hohenwarter A, Catoor D, et al. A fracture-resistant 
high-entropy alloy for cryogenic applications. Science, 2014, 345: 1153-1158

38 Tang Z, Yuan T, Tsai C, et al. Fatigue behavior of a wrought $\mathrm{Al}_{0.5} \mathrm{CoCrCuFeNi}$ two-phase high-entropy alloy. Acta Mater, 2015, 99: 247-258

39 Hemphill M, Yuan T, Wang G, et al. Fatigue behavior of $\mathrm{Al}_{0.5}$ CoCrCuFeNi high entropy alloys. Acta Mater, 2012, 60: 57235734

40 Gao MC, Yeh JW, Liaw PK, et al. High-Entropy Alloys: Fundamentals and Applications. Switzerland: Springer, 2016

41 Murty BS, Yeh JW, Ranganathan S. High-Entropy Alloys. Oxford: Butterworth-Heinemann, 2014

42 Ye Y, Wang Q, Lu J, et al. High-entropy alloy: challenges and prospects. Mater Today, 2016, 19: 349-362

43 Shi Y, Yang B, Liaw P. Corrosion-resistant high-entropy alloys: a review. Metals, 2017, 7: 43

44 Gao M, Gao P, Hawk J, et al. Computational modeling of highentropy alloys: structures, thermodynamics and elasticity. J Mater Res, 2017, 32: 3627-3641

45 Diao H, Feng R, Dahmen K, et al. Fundamental deformation behavior in high-entropy alloys: an overview. Curr Opin Solid State Mater Sci, 2017, 21: 252-266

46 Zhou Y, Zhang Y, Wang Y, et al. Microstructure and compressive properties of multicomponent $\mathrm{Al}_{x}(\mathrm{TiVCrMnFeCoNiCu})_{100-x}$ high-entropy alloys. Mater Sci Eng-A, 2007, 454-455: 260-265

$47 \mathrm{He} \mathrm{J}$, Wang $\mathrm{H}$, Huang $\mathrm{H}$, et al. A precipitation-hardened highentropy alloy with outstanding tensile properties. Acta Mater, 2016, 102: 187-196

48 Yeh J. Alloy design strategies and future trends in high-entropy alloys. JOM, 2013, 65: 1759-1771

49 Guo S, Hu Q, Ng C, et al. More than entropy in high-entropy alloys: forming solid solutions or amorphous phase. Intermetallics, 2013, 41: 96-103

50 Zhang $\mathrm{Y}, \mathrm{Lu} \mathrm{Z}$, Ma S, et al. Guidelines in predicting phase formation of high-entropy alloys. MRC, 2014, 4: 57-62

51 Yang X, Zhang Y. Prediction of high-entropy stabilized solidsolution in multi-component alloys. Mater Chem Phys, 2012, 132: 233-238

52 Borkar T, Gwalani B, Choudhuri D, et al. A combinatorial assessment of $\mathrm{Al}_{x} \mathrm{CrCuFeNi}_{2}(0<x<1.5)$ complex concentrated alloys: microstructure, microhardness, and magnetic properties. Acta Mater, 2016, 116: 63-76

$53 \mathrm{Ng} \mathrm{C}$, Guo S, Luan J, et al. Entropy-driven phase stability and slow diffusion kinetics in an $\mathrm{Al}_{0.5} \mathrm{CoCrCuFeNi}$ high entropy alloy. Intermetallics, 2012, 31: 165-172

54 Prasad H, Singh S, Panigrahi B. Mechanical activated synthesis of alumina dispersed FeNiCoCrAlMn high entropy alloy. J Alloys Compd, 2017, 692: 720-726

55 Kao Y, Chen T, Chen S, et al. Microstructure and mechanical property of as-cast, -homogenized, and -deformed $\mathrm{Al}_{x} \mathrm{CoCrFeNi}$ $(0 \leq x \leq 2)$ high-entropy alloys. J Alloys Compd, 2009, 488: 57-64

56 Huang $\mathrm{Y}$, Chen $\mathrm{L}$, Lui $\mathrm{H}$, et al. Microstructure, hardness, resistivity and thermal stability of sputtered oxide films of Al$\mathrm{CoCrCu}_{0.5} \mathrm{NiFe}$ high-entropy alloy. Mater Sci Eng-A, 2007, 457: $77-83$

57 Tung C, Yeh J, Shun T, et al. On the elemental effect of AlCoCrCuFeNi high-entropy alloy system. Mater Lett, 2007, 61: 1-5

58 Jiang $\mathrm{L}, \mathrm{Lu} \mathrm{Y}, \mathrm{Wu} \mathrm{W}$, et al. Microstructure and mechanical properties of a CoFeNi $\mathrm{V}_{0.5} \mathrm{Nb}_{0.75}$ eutectic high entropy alloy in ascast and heat-treated conditions. J Mater Sci Tech, 2016, 32: 245-
250

59 Santodonato L, Zhang Y, Feygenson M, et al. Deviation from high-entropy configurations in the atomic distributions of a multi-principal-element alloy. Nat Commun, 2015, 6: 5964

60 Zhang K, Fu Z, Zhang J, et al. Annealing on the structure and properties evolution of the CoCrFeNiCuAl high-entropy alloy. J Alloys Compd, 2010, 502: 295-299

61 Lin $\mathrm{C}$, Tsai $\mathrm{H}$, Bor $\mathrm{H}$. Effect of aging treatment on microstructure and properties of high-entropy $\mathrm{Cu}_{0.5} \mathrm{CoCrFeNi}$ alloy. Intermetallics, 2010, 18: 1244-1250

62 Otto F, Dlouhý A, Somsen C., et al. The influences of temperature and microstructure on the tensile properties of a $\mathrm{CoCrFeMnNi}$ high-entropy alloy. Acta Mater, 2013, 61: 5743-5755

63 Kuznetsov A, Shaysultanov D, Stepanov N, et al. Tensile properties of an $\mathrm{AlCrCuNiFeCo}$ high-entropy alloy in as-cast and wrought conditions. Mater Sci Eng-A, 2012, 533: 107-118

64 Barber Z, Blamire M. High throughput thin film materials science. Mater Sci Tech, 2008, 24: 757-770

65 Ma D, Yao M, Pradeep K, et al. Phase stability of non-equiatomic CoCrFeMnNi high entropy alloys. Acta Mater, 2015, 98: 288-296

66 Gebhardt T, Music D, Takahashi T, et al. Combinatorial thin film materials science: from alloy discovery and optimization to alloy design. Thin Solid Films, 2012, 520: 5491-5499

67 Miracle D, Majumdar B, Wertz K, et al. New strategies and tests to accelerate discovery and development of multi-principal element structural alloys. Scripta Mater, 2017, 127: 195-200

68 Waseem O, Ryu H. Powder metallurgy processing of a $\mathrm{W}_{x} \mathrm{TaTiVCr}$ high-entropy alloy and its derivative alloys for fusion material applications. Sci Rep, 2017, 7: 1926

69 Senkov O, Miller J, Miracle D, et al. Accelerated exploration of multi-principal element alloys with solid solution phases. Nat Commun, 2015, 6: 6529

70 Wang $\mathrm{W}$, Wang $\mathrm{W}$, Wang $\mathrm{S}$, et al. Effects of $\mathrm{Al}$ addition on the microstructure and mechanical property of $\mathrm{Al}_{x} \mathrm{CoCrFeNi}$ highentropy alloys. Intermetallics, 2012, 26: 44-51

71 Maiti S, Steurer W. Structural-disorder and its effect on mechanical properties in single-phase TaNbHfZr high-entropy alloy. Acta Mater, 2016, 106: 87-97

72 Tsau C, Chang Y. Microstructures and mechanical properties of $\mathrm{TiCrZrNbN}_{x}$ alloy nitride thin films. Entropy, 2013, 15: 50125021

73 Li C, Li J, Zhao M, et al. Effect of alloying elements on microstructure and properties of multiprincipal elements high-entropy alloys. J Alloys Compd, 2009, 475: 752-757

74 Wang W, Wang W, Yeh J. Phases, microstructure and mechanical properties of $\mathrm{Al}_{x} \mathrm{CoCrFeNi}$ high-entropy alloys at elevated temperatures. J Alloys Compd, 2014, 589: 143-152

75 Zhao K, Xia X, Bai H, et al. Room temperature homogeneous flow in a bulk metallic glass with low glass transition temperature. Appl Phys Lett, 2011, 98: 141913

76 Stefanescu D. Science and Engineering of Casting Solidification. Switzerland: Springer, 2015

77 Lv Y, Hu R, Yao Z, et al. Cooling rate effect on microstructure and mechanical properties of $\mathrm{Al}_{x} \mathrm{CoCrFeNi}$ high entropy alloys. Mater Des, 2017, 132: 392-399

78 Singh S, Wanderka N, Murty B, et al. Decomposition in multicomponent AlCoCrCuFeNi high-entropy alloy. Acta Mater, 2011, 59: $182-190$

79 Ma S, Zhang S, Gao M, et al. A successful synthesis of the $\mathrm{CoCrFeNiAl} l_{0.3}$ single-crystal, high-entropy alloy by Bridgman 
solidification. JOM, 2013, 65: 1751-1758

80 Guo S, Ng C, Liu C. Anomalous solidification microstructures in Co-free $\mathrm{Al}_{x} \mathrm{CrCuFeNi}_{2}$ high-entropy alloys. J Alloys Compd, 2013, 557: 77-81

81 Ma S, Zhang Y. Effect of $\mathrm{Nb}$ addition on the microstructure and properties of AlCoCrFeNi high-entropy alloy. Mater Sci Eng-A, 2012, 532: 480-486

82 Senkov O, Wilks G, Scott J, et al. Mechanical properties of $\mathrm{Nb}_{25}$ $\mathrm{Mo}_{25} \mathrm{Ta}_{25} \mathrm{~W}_{25}$ and $\mathrm{V}_{20} \mathrm{Nb}_{20} \mathrm{Mo}_{20} \mathrm{Ta}_{20} \mathrm{~W}_{20}$ refractory high entropy alloys. Intermetallics, 2011, 19: 698-706

83 Tong C, Chen M, Yeh J, et al. Mechanical performance of the $\mathrm{Al}_{x} \mathrm{CoCrCuFeNi}$ high-entropy alloy system with multiprincipal elements. Metall Mat Trans A, 2005, 36: 1263-1271

84 Kumar N, Ying Q, Nie X, et al. High strain-rate compressive deformation behavior of the $\mathrm{Al}_{0.1} \mathrm{CrFeCoNi}$ high entropy alloy. Mater Des, 2015, 86: 598-602

85 Salishchev G, Tikhonovsky M, Shaysultanov D, et al. Effect of Mn and $\mathrm{V}$ on structure and mechanical properties of high-entropy alloys based on CoCrFeNi system. J Alloys Compd, 2014, 591: 11-21

86 Chen Z, Chen W, Wu B, et al. Effects of Co and Ti on microstructure and mechanical behavior of $\mathrm{Al}_{0.75} \mathrm{FeNiCrCo}$ high entropy alloy prepared by mechanical alloying and spark plasma sintering. Mater Sci Eng-A, 2015, 648: 217-224

87 He J, Liu W, Wang $\mathrm{H}$, et al. Effects of $\mathrm{Al}$ addition on structural evolution and tensile properties of the FeCoNiCrMn high-entropy alloy system. Acta Mater, 2014, 62: 105-113

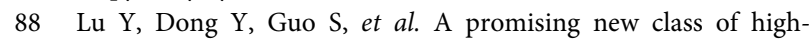
temperature alloys: eutectic high-entropy alloys. Sci Rep, 2015, 4: 6200

89 Yasuda $\mathrm{H}$, Shigeno $\mathrm{K}$, Nagase $\mathrm{T}$. Dynamic strain aging of $\mathrm{Al}_{0.3}$ CoCrFeNi high entropy alloy single crystals. Scripta Mater, 2015, 108: $80-83$

90 Lu Y, Gao X, Jiang L, et al. Directly cast bulk eutectic and neareutectic high entropy alloys with balanced strength and ductility in a wide temperature range. Acta Mater, 2017, 124: 143-150

91 Shi Y, Yang B, Xie X, et al. Corrosion of $\mathrm{Al}_{x} \mathrm{CoCrFeNi}$ highentropy alloys: Al-content and potential scan-rate dependent pitting behavior. Corrosion Sci, 2017, 119: 33-45

92 Tang Z, Huang L, He W, et al. Alloying and processing effects on the aqueous corrosion behavior of high-entropy alloys. Entropy, 2014, 16: 895-911

93 Hsu Y, Chiang W, Wu J. Corrosion behavior of $\mathrm{FeCoNiCrCu}_{x}$ high-entropy alloys in $3.5 \%$ sodium chloride solution. Mater Chem Phys, 2005, 92: 112-117

94 Lee C, Chen Y, Hsu C, et al. The effect of boron on the corrosion resistance of the high entropy alloys $\mathrm{Al}_{0.5} \mathrm{CoCrCuFeNiB}_{x}$. J Electrochem Soc, 2007, 154: C424

95 Zou Y, Wheeler J, Ma H, et al. Nanocrystalline high-entropy alloys: a new paradigm in high-temperature strength and stability. Nano Lett, 2017, 17: 1569-1574

96 Sathiyamoorthi P, Basu J, Kashyap S, et al. Thermal stability and grain boundary strengthening in ultrafine-grained $\mathrm{CoCrFeNi}$ high entropy alloy composite. Mater Des, 2017, 134: 426-433

97 Kumar N, Li C, Leonard K, et al. Microstructural stability and mechanical behavior of FeNiMnCr high entropy alloy under ion irradiation. Acta Mater, 2016, 113: 230-244

98 Xia S, Yang $\mathrm{X}$, Yang $\mathrm{T}$, et al. Irradiation resistance in $\mathrm{Al}_{x} \mathrm{CoCrFeNi}$ high entropy alloys. JOM, 2015, 67: 2340-2344

99 Nagase T, Anada S, Rack P, et al. Electron-irradiation-induced structural change in $\mathrm{Zr}-\mathrm{Hf}-\mathrm{Nb}$ alloy. Intermetallics, 2012, 26 : 122-130

100 Jin K, Lu C, Wang L, et al. Effects of compositional complexity on the ion-irradiation induced swelling and hardening in $\mathrm{Ni}$-containing equiatomic alloys. Scripta Mater, 2016, 119: 65-70

101 Zhang Y, Stocks G, Jin K, et al. Influence of chemical disorder on energy dissipation and defect evolution in concentrated solid solution alloys. Nat Commun, 2015, 6: 8736

102 Ullah M, Aidhy D, Zhang Y, et al. Damage accumulation in ionirradiated Ni-based concentrated solid-solution alloys. Acta Mater, 2016, 109: 17-22

103 He M, Wang S, Shi S, et al. Mechanisms of radiation-induced segregation in CrFeCoNi-based single-phase concentrated solid solution alloys. Acta Mater, 2017, 126: 182-193

104 Zhao F, Wang $\mathrm{H}$, Wu Y, et al. Thermoelectric performance of PbSnTeSe high-entropy alloys. Mater Res Lett, 2017, 5: 187-194

105 Poletti M, Fiore G, Gili F, et al. Development of a new high entropy alloy for wear resistance: $\mathrm{FeCoCrNiW}_{0.3}$ and $\mathrm{Fe}$ $\mathrm{CoCrNiW}_{0.3}+5$ at.\% of C. Mater Des, 2017, 115: 247-254

Zhang Y, Zuo TT, Cheng YQ, et al. High-entropy alloys with high saturation magnetization, electrical resistivity and malleability. Sci Rep, 2013, 3: 1455

107 Zuo T, Yang X, Liaw P, et al. Influence of Bridgman solidification on microstructures and magnetic behaviors of a non-equiatomic FeCoNiAlSi high-entropy alloy. Intermetallics, 2015, 67: 171-176

108 Green M, Choi C, Hattrick-Simpers J, et al. Fulfilling the promise of the materials genome initiative with high-throughput experimental methodologies. Appl Phys Rev, 2017, 4: 011105

109 Drosback M. Materials genome initiative: advances and initiatives. JOM, 2014, 66: 334-335

110 Jain A, Persson K, Ceder G. Research update: the materials genome initiative: data sharing and the impact of collaborative $a b$ initio databases. APL Mater, 2016, 4: 053102

111 Stan M. Discovery and design of nuclear fuels. Mater Today, 2009, 12: 20-28

112 Troparevsky M, Morris J, Kent P, et al. Criteria for predicting the formation of single-phase high-entropy alloys. Phys Rev X, 2015, 5: 011041

113 Rao J, Diao H, Ocelík V, et al. Secondary phases in $\mathrm{Al}_{x} \mathrm{CoCrFeNi}$ high-entropy alloys: an in-situ TEM heating study and thermodynamic appraisal. Acta Mater, 2017, 131: 206-220

114 Liu S, Gao M, Liaw P, et al. Microstructures and mechanical properties of $\mathrm{Al}_{x} \mathrm{CrFeNiTi}_{0.25}$ alloys. J Alloys Compd, 2015, 619: 610-615

115 Tang Z, Gao M, Diao H, et al. Aluminum alloying effects on lattice types, microstructures, and mechanical behavior of highentropy alloys systems. JOM, 2013, 65: 1848-1858

116 Feng R, Gao M, Lee C, et al. Design of light-weight high-entropy alloys. Entropy, 2016, 18: 333

117 Saal J, Berglund I, Sebastian J, et al. Equilibrium high entropy alloy phase stability from experiments and thermodynamic modeling. Scripta Mater, 2018, 146: 5-8

118 Guo S, Ng C, Lu J, et al. Effect of valence electron concentration on stability of fcc or bcc phase in high entropy alloys. J Appl Phys, 2011, 109: 103505-103505

119 Kaufman L, Ågren J. CALPHAD, first and second generationbirth of the materials genome. Scripta Mater, 2014, 70: 3-6

120 Zhang C, Zhang F, Chen S, et al. Computational thermodynamics aided high-entropy alloy design. JOM, 2012, 64: 839-845

121 Zaddach A, Niu C, Koch C, et al. Mechanical properties and 
stacking fault energies of $\mathrm{NiFeCrCoMn}$ high-entropy alloy. JOM, 2013, 65: 1780-1789

122 Ye Y, Liu C, Yang Y. A geometric model for intrinsic residual strain and phase stability in high entropy alloys. Acta Mater, 2015, 94: 152-161

123 Zhang C, Zhang F, Jin K, et al. Understanding of the elemental diffusion behavior in concentrated solid solution alloys. J Phase Equilib Diffus, 2017, 38: 434-444

124 Meystre P, Sargent M. Elements of Quantum Optics. Heidelberg: Springer-Verlag Berlin Heidelberg, 2013

125 Glimm J, Jaffe A. Quantum Physics: a Functional Integral Point of View. New York: Springer-Verlag, 2012

126 Snyder J, Rupp M, Hansen K, et al. Finding density functionals with machine learning. Phys Rev Lett, 2012, 108: 253002

127 Ryabinkin I, Kohut S, Staroverov V. Reduction of electronic wave functions to Kohn-Sham effective potentials. Phys Rev Lett, 2015, 115: 083001

128 Curtarolo S, Hart G, Nardelli M, et al. The high-throughput highway to computational materials design. Nat Mater, 2013, 12: 191-201

129 Zuo T, Gao M, Ouyang L, et al. Tailoring magnetic behavior of CoFeMnNiX (X = Al, Cr, Ga, and $\mathrm{Sn}$ ) high entropy alloys by metal doping. Acta Mater, 2017, 130: 10-18

130 Ma D, Grabowski B, Körmann F, et al. Ab initio thermodynamics of the CoCrFeMnNi high entropy alloy: importance of entropy contributions beyond the configurational one. Acta Mater, 2015, 100: 90-97

131 Jiang C, Uberuaga B. Efficient ab initio modeling of random multicomponent alloys. Phys Rev Lett, 2016, 116: 105501

132 Widom M, Huhn W, Maiti S, et al. Hybrid Monte Carlo/molecular dynamics simulation of a refractory metal high entropy alloy. Metall Mat Trans A, 2014, 45: 196-200

133 Toda-Caraballo I, Wróbel J, Nguyen-Manh D, et al. Simulation and modeling in high entropy alloys. JOM, 2017, 69: 2137-2149

134 Feng W, Qi Y, Wang S. Effects of short-range order on the magnetic and mechanical properties of $\mathrm{FeCoNi}(\mathrm{AlSi})_{x}$ high entropy alloys. Metals, 2017, 7: 482

135 Tian F, Varga L, Vitos L. Predicting single phase CrMoWX high entropy alloys from empirical relations in combination with firstprinciples calculations. Intermetallics, 2017, 83: 9-16

136 Choudhury S, Barnard L, Tucker J, et al. Ab-initio based modeling of diffusion in dilute bcc $\mathrm{Fe}-\mathrm{Ni}$ and $\mathrm{Fe}-\mathrm{Cr}$ alloys and implications for radiation induced segregation. J Nucl Mater, 2011, 411: 1-14 137 Smith T, Hooshmand M, Esser B, et al. Atomic-scale characterization and modeling of $60^{\circ}$ dislocations in a high-entropy alloy. Acta Mater, 2016, 110: 352-363

138 Chen H-, Mao H, Chen Q. Database development and Calphad calculations for high entropy alloys: Challenges, strategies, and tips. Mater Chem Phys, 2017

$139 \mathrm{Wu} \mathrm{W}, \mathrm{Ni} \mathrm{S}$, Liu Y, et al. Effects of cold rolling and subsequent annealing on the microstructure of a HfNbTaTiZr high-entropy alloy. J Mater Res, 2016, 31: 3815-3823

140 Li Z, Pradeep K, Deng Y, et al. Metastable high-entropy dualphase alloys overcome the strength-ductility trade-off. Nature, 2016, 10: 227-230

141 Yan X, Li J, Zhang W, et al. A brief review of high-entropy films. Mater Chem Phys, 2017

142 Xia S, Gao M, Yang T, et al. Phase stability and microstructures of high entropy alloys ion irradiated to high doses. J Nucl Mater, 2016, 480: 100-108

143 Jhong Y, Huang C, Lin S. Effects of $\mathrm{CH}_{4}$ flow ratio on the structure and properties of reactively sputtered $(\mathrm{CrNbSiTiZr}) \mathrm{C}_{x}$ coatings. Mater Chem Phys, 2017

144 Feng X, Zhang J, Xia Z, et al. Stable nanocrystalline NbMoTaW high entropy alloy thin films with excellent mechanical and electrical properties. Mater Lett, 2018, 210: 84-87

145 Sheng W, Yang X, Wang C, et al. Nano-crystallization of highentropy amorphous $\mathrm{NbTiAlSiW}_{x} \mathrm{~N}_{y}$ films prepared by magnetron sputtering. Entropy, 2016, 18: 226

146 Zhang Y, Liu J, Chen S, et al. Serration and noise behaviors in materials. Prog Mater Sci, 2017, 90: 358-460

147 Carroll R, Lee C, Tsai C -, et al. Experiments and model for serration statistics in low-entropy, medium-entropy, and highentropy alloys. Sci Rep, 2015, 5: 16997

Acknowledgements This work was supported by the National Natural Science Foundation of China (51471025 and 51671020).

Author contributions Zhang $\mathrm{W}$ prepared the manuscript under the direction of Zhang Y. Zhang Y and Liaw PK revised the manuscript. All authors contributed to the general discussion.

Conflict of interest The authors declare no conflict of interest. 

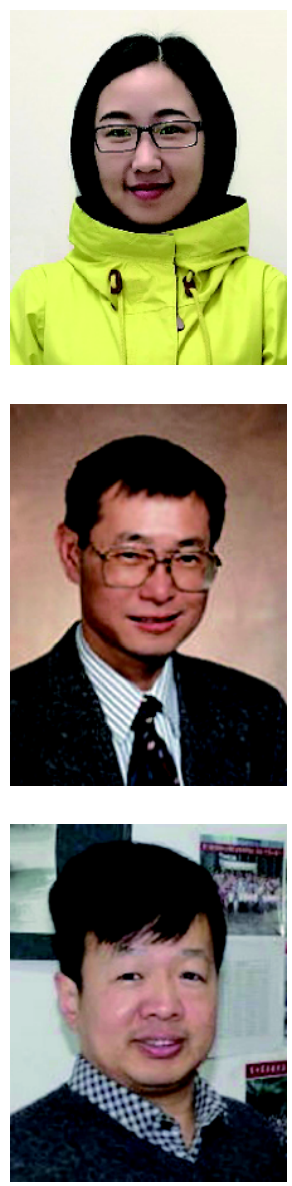

Weiran Zhang is a PhD student at the State Key Laboratory for Advanced Metals and Materials, University of Science \& Technology Beijing (USTB), under Prof. Zhang's supervision. Her interest focuses on the low-activation of high-entropy alloys and DFT.
Peter K. Liaw obtained his BSc degree in physics from Tsing Hua University, Taiwan, and his $\mathrm{PhD}$ in materials science and engineering from the Northwestern University. After working at Westinghouse Research and Development (R\&D) Center for thirteen years, he joined the faculty and became an Endowed Ivan Racheff Chair of Excellence in the Department of Materials Science and Engineering at the University of Tennessee (UT), Knoxville. He has been working in the areas of fatigue, fracture, nondestructive evaluation, and life-prediction methodologies of structural alloys and composites. Since joining UT, his research interests include mechanical behavior, nondestructive evaluation, biomaterials, high-temperature alloys, bulk metallic glasses, high-entropy alloys, ceramic-matrix composites and coatings. He has published 890 peer-reviewed papers, edited more than 30 books.

Yong Zhang has been a full professor of the USTB \& State Key Laboratory for Advanced Metals and Materials since 2004. He attained his Bachelor degree at Yanshan University in 1991, majored in materials science. He obtained Master degree majored in nuclear materials in 1993, and PhD in composite materials in 1998 at the USTB. Then he worked as a postdoctoral fellow in the Institute of Physics, Chinese Academy of Science, and Singapore-Massachusettes Institute of Technology (MIT) Alliance (SMA). His interest focuses on high-entropy materials and serration behaviors.

\section{高熵合金材料研究进展}

张蔚再 ${ }^{1}$, Peter K. Liaw ${ }^{2}$, 张勇 ${ }^{1,3^{*}}$

摘要 根据人类开发材料的能力来看, 合金成分经历了从简单到复杂的发展过程. 合金的功能和性能不断改善, 同时促进了人类文明进步. 具有多组分的高熵合金(HEAs) 可以有效地改善合金的微观结构和性质. 高摘合金具有诸如高强度和高硬度、优异的耐腐蚀性和热稳定 性、良好的抗疲劳强度及断裂强度、强耐辐射性等优异的性能, 这是传统的合金无法比拟的. 这些优异的性能也说明高熵合金未来具有 非常高的应用前景. 近年来, 高熵合金在各个领域也呈现出快速发展的趋势. 为了更好地了解高熵合金的基础, 未来快速开发出具有更加 优异性能的高熵合金, 本文综述了近年来关于高熵合金的发展. 高熵合金的发展已经经历了两个阶段, 第一个阶段为等摩尔-单相固溶体 结构的高熵合金，第二阶段为非等摩尔比的多相固溶体高熵合金. 本文主要讨论了高熵合金的制备方法、组分设计、相形成和微观结 构、优异的性能和高熵合金在计算模拟方面的应用, 同时提出了高熵合金的未来发展趋势和前景. 